\title{
A decade of Indium-catalyzed multicomponent reactions (MCRs)
}

Pedro Brandão, ${ }^{* a, b]}$ Anthony J. Burke, ${ }^{[b]}$ and Marta Pineiro ${ }^{[a]}$

[a] MSc P. Brandão and Prof. Dr. M. Pineiro

University of Coimbra

CQC and Deparment of Chemistry

3004-535 Coimbra, Portugal

E-mail: pbrandao@qui.uc.pt, http://orcid.org/0000-0002-1455-7470

[b] MSc P. Brandão and Prof. Dr. Anthony J. Burke

Centro de Química de Évora and LAQV-REQUIMTE

University of Évora

7000-671 Évora, Portugal 
Pedro Brandão received his MSc in Pharmaceutical Sciences from the Faculty of Pharmacy - University of Porto, in 2011. Highly committed to the field of Drug Discovery, he is currently undergoing his $\mathrm{PhD}$ studies in Chemistry, in the field of Catalysis and Sustainability. His main focus of work is the discovery of new drug candidates, applying sustainable catalytic methodologies in multicomponent reactions. (Orcid ID: http://orcid.org/0000-0002-1455-7470).

Anthony J. Burke is an associate professor with aggregation at the University of Evora. Has over 130 publications/communications/patents, has coordinated many projects and supervised several students. Has a successful track record in drug discovery in the area of Alzheimer's disease and a strong interest in sustainable catalytic processes to achieve this objective. He founded Chiratecnics in 2009 and is the founding chairman of the International Symposium on Synthesis and Catalysis series, an editor at Open Chemistry (De Gruyter) and a Chemistry Europe fellow.

Marta Pineiro studied chemistry at the University of Santiago de Compostela, Spain. She received her Ph.D. in Organic Chemistry in 2003 in the University of Coimbra, Portugal. Since 2002 has been enrolled at the University of Coimbra, being at present Auxiliary Professor. Her research interests are in the area of Green Chemistry and Sustainable Organic Synthesis. The main focus of her research is the development of microwave-assisted synthesis and mechanochemistry processes for


the preparation of Heterocycles with biological activity.






\section{A decade of Indium-catalyzed multicomponent reactions (MCRs)}

Pedro Brandão, ${ }^{a, b}$ Anthony J. Burke ${ }^{b}$ and Marta Pineiro ${ }^{a}$

a University of Coimbra, CQC, Department of Chemistry, 3004-535 Coimbra, Portugal

b Centro de Química de Évora and LAQV-REQUIMTE, University of Évora, 7000 Évora, Portugal

\section{ABSTRACT (150 Words)}

In the context of synthetic chemistry, Indium is one of the least explored elements of the notorious group 13 of the periodic table, and hasn't attracted quite the same amount of attention as its fellow members, Aluminium and Boron, which have shown unprecedented synthetic applications for more than a half a century. Nonetheless, Indium has emerged in recent years as a very valuable catalyst for multicomponent reactions. From the use of indium powder or easily accessible and cheap indium salts, to more complex indium-based metal organic frameworks or nanoparticles, a plethora of applications have been described throughout this last decade, showcasing not only the versatility of indium catalysis, but also how much there is still to be explored. In the aftermath of the international year of the periodic table of the chemical elements in 2019, we navigated through the large inventory of multicomponent reactions (MCRs) in an effort to encounter the types of useful reactions leading to important target compounds (many of which being biologically active) catalyzed by this $d$-block post-transition metal. 


\section{INTRODUCTION}

Indium was discovered by German chemists Ferdinand Reich and Theodor Richter in 1863 and successfully isolated one year later, and named indium due to the indigo colored line of its spectrum. ${ }^{[1]}$ With atomic number 49 , placed in period 5 and group 13 , this $d$-block post-transition metal caught the attention of researchers in the field of organic chemistry and catalysis in the early 1990s, due to the Lewis acidity of group 13 metal complexes. ${ }^{[2]}$

The range of chemical transformations catalyzed by indium and its derivatives has been widening through time, as the physical chemical properties of this metal becomes clearer and more desirable from a sustainability point of view. Several advantages can be attributed to indium, since it is easy to handle, stable to air and moisture (a clear disadvantage of many other metal catalysts) and non-toxic. Further, its stability, recyclability and high tolerance to a wide diversity of chemical substrates and functional groups, makes indium-based catalysts virtually almost the perfect Lewis acid catalyst. These properties make them suitable for a wide range of chemical transformations, including reactions in the presence of water. ${ }^{[3]}$ The catalytic effect of indium(III)-based catalysts is highly focused on its $\sigma$-coordination with carbonyl derivatives, although it can also be employed as a $\pi$-acid catalyst of carbon-carbon unsaturated systems, leading to its electrophilic activation. ${ }^{[4]}$

Considering the trivalent cationic nature of indium in its salt form, a comparison of this post-transition metal with rare-earth metals, and lanthanides in particular, is of utmost relevance, since these elements also generate trivalent cations and are very desirable for MCRs catalysis. Despite the well-established application of these rare-earth metals in MCRs, indium presents several advantages for catalytic purposes, as it is often cheaper, easier to handle, stable to moisture and air and it is suitable for a wide range of chemical transformations, mostly due to its low first ionization potential, which makes it a perfect candidate for single-electron transfer reactions, and its low heterophilicity, which makes indium catalysts ideal for C-C bond formation reactions and tolerant for multiple functional groups, hence very desirable for multicomponent approaches. ${ }^{[5]}$

The counterion is also a very relevant feature of indium-based catalysts, with indium(III) halides presenting a more carbophilic nature, while indium(III) triflate displays a higher oxophilicity, being often designated as a harder catalyst. The later one is also more expensive than the halide forms, and is often considered a Lewis superacid (together with indium(III) triflimidate), since the delocalisation of the counterion leads to a higher exposure of the metal cation and catalytic sites, enhancing the Lewis acid properties of this metal center, which explains why in many observed cases, indium triflate outperforms the indium halides. ${ }^{[4,6]}$ 
Over recent years, several review publications have described the relevance of indium halides, indium salts, organoindium compounds and indium metal-organic frameworks (MOFs) in homogeneous and heterogeneous catalysis. ${ }^{[7]}$ Also in the field of asymmetric catalysis, indium associated to different chiral ligands proved to be efficient for several asymmetric chemical transformations, however its application in asymmetric MCRs is still undeveloped, with just a few examples describing diastereoselective multicomponent transformations catalyzed by indium salts, namely Mannich-type and Reformatsky-type reactions, with the stereoselectivity induced by the chiral substrates. ${ }^{[8]}$ Nonetheless, a thorough review on the application of indium-based catalysts in multicomponent reactions (MCRs) is long overdue, since the last general review focused on this topic dates back to 2010. ${ }^{[5 a]}$ with a more specific review by Singh et al. in 2012 on the application of indium(III) chloride as catalyst. ${ }^{[9]}$ Since MCRs can be described as a great synthetic tool to obtain molecular diversity under good atom, pot and step economy, with applications in several fields, such as natural products total synthesis, medicinal chemistry and polymer chemistry. ${ }^{[10]}$

With this in mind, in the aftermath of the international year of the periodic table of the chemical elements in 2019, we aim with this review to access the chemical knowledge unlocked in the past decade where indium-catalysis and MCRs converge, placing the $49^{\text {th }}$ element in the spotlight.

\section{Isocyanide-based MCRs}

Isocyanide-based MCRs, such as the Ugi, Passerini and Groebke-BlackburnBienayme (GBB) reactions are widely employed in medicinal chemistry and drug discovery, since they allow researchers to obtain in one-step three or four-component reactions a plethora of new compounds bearing newly formed amide and ester bonds, or even leading to heterocycle formation. ${ }^{[11]}$ Firstly, addressing the Ugi four-component reaction, that involves the formation of two new amide bonds in the final products, involving an isocyanide, a primary amine, a carbonyl compound and a carboxylic acid (Scheme 1). ${ }^{[12]}$

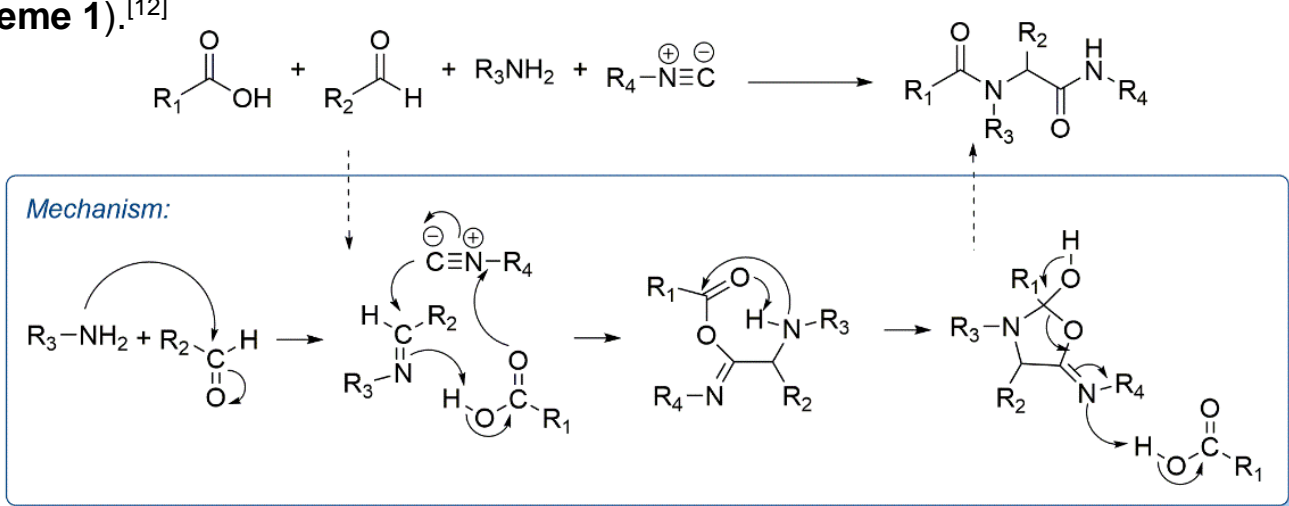

Scheme 1: Mechanistic insights of a classic Ugi reaction. 
Several efforts have been made in recent years on the development of efficient catalytic versions of the Ugi reaction, as was recently reviewed by our group. ${ }^{[13]}$ Lewis acid catalysis is one of the most explored in this reaction, and the application of indium(III) chloride as a cheap and easy to handle catalyst is often reported (Scheme 2). Ibarra-Rivera et al. reported the use of this catalyst in the preparation of Ugi adducts (7 examples), in excellent yields (Scheme 2A). The obtained products were further transformed into tetrahydroindeno[1,2-b]pyrrolidine derivatives, via a palladiumcatalyzed aerobic oxidative cyclization, in low to moderate yields. ${ }^{[14]}$

The sustainability of synthetic processes has become one of the most important features of chemical transformations in the $21^{\text {st }}$ century. The application of novel synthetic methodologies, such as microwave-assisted organic synthesis (MAOS) or mechanochemistry, became increasingly widespread in various R\&D units (including our own). The catalytic Ugi reaction is no exception to this trend, as reported by PolindaraGarcia and co-workers. MAOS was applied in the synthesis of Ugi adducts (18 examples) in the presence of indium(III) chloride, affording the target compounds in moderate to good yields (Scheme 2B). The products were then further transformed into cotinine analogs with potential bioactivity, via a base-promoted cyclization reaction between the peptidyl position and the 3-chloropropionic side chain of the Ugi adduct, affording a y-lactam ring. Iso-cotinine analogs (12 examples) were also obtained, using a one-step Ugi-reaction, applying 2- and 4-pyridinecarboxaldehydes as starting materials (Scheme 2C). ${ }^{[15]}$ In another example by the same research group, the Ugi reaction was employed as the first synthetic step to obtain a library of 1,2-disubstituted-cis-3,4dihydroxypyrrolidines. The synthetic intermediates (18 examples) were prepared in moderate to good yields using low catalyst loading and unusual long reaction times under microwave irradiation (Scheme 2D), and could be further transformed into the desired compounds via a 5-endo-dig cycloisomerization, followed by a cis-dihydroxylation. ${ }^{[16]}$

Polindara-García and Juaristi reported the application of mechanochemical activation through high-speed ball milling (HSBM) in the Ugi and Passerini reactions, with the first one occurring in the presence of a low catalyst loading of indium(III) chloride (2 mol\%). During their optimization process, the authors verified that the presence of a small amount of methanol improved the yields (usually termed liquid-assisted grinding process). The small library (16 examples) could then be prepared in moderate to good yields using this sustainable methodology, comparable to those obtained under microwave irradiation or at room temperature conditions for several examples. Noteworthy is also the fact that when the reaction was performed using $p$ nitrobenzaldehyde, $p$-dimethylaminebenzaldehyde or pyrrolcarboxyaldehyde as starting 
material, agate jars were required instead of stainless steel jars, in order to avoid decomposition during the reaction (Scheme 2E). ${ }^{[17]}$

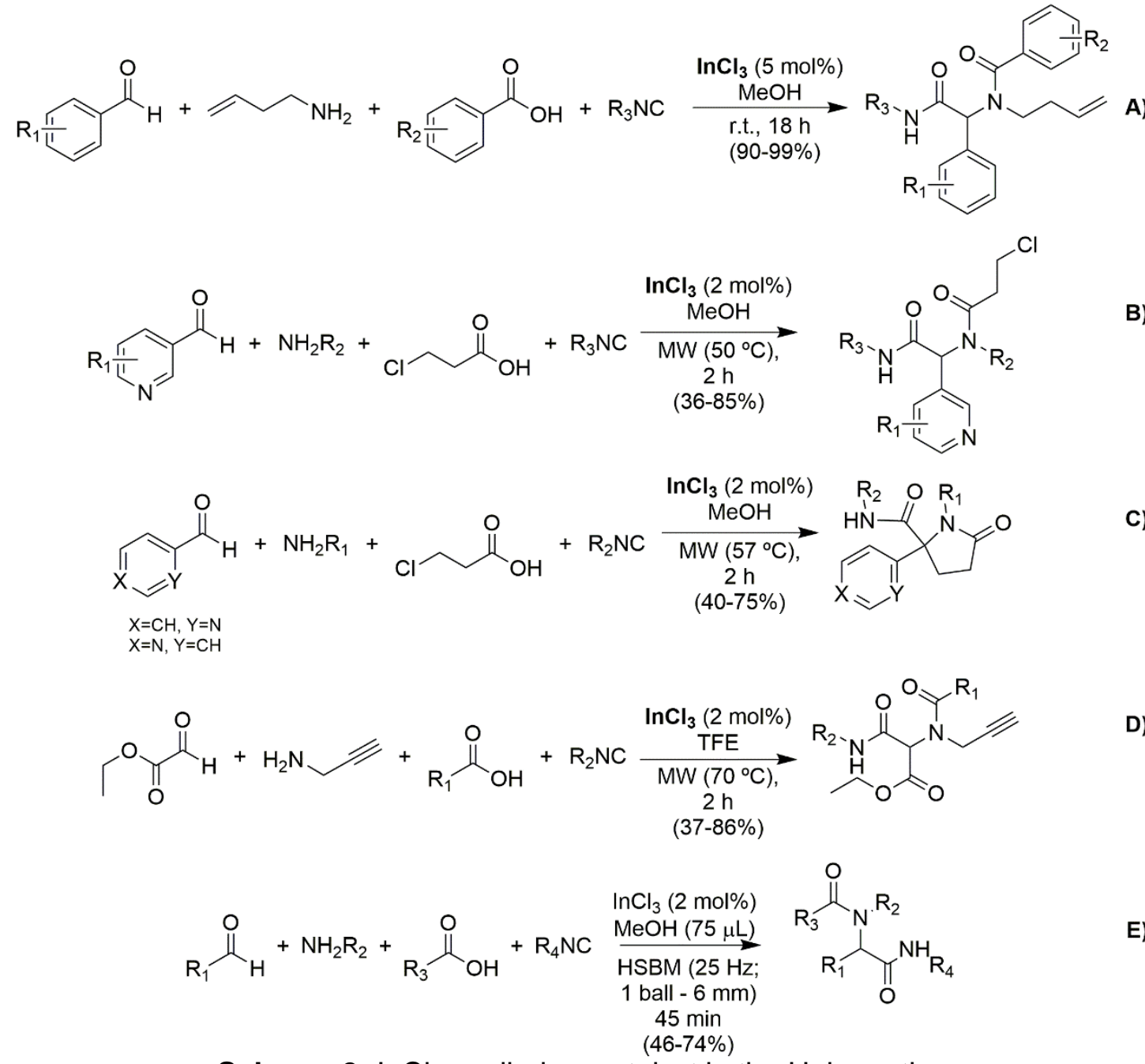

Scheme 2: $\operatorname{InCl}_{3}$ applied as catalyst in the Ugi reaction

( $\mathrm{MW}=$ microwave; TFE=2,2,2-trifluoroethanol).

The already mentioned Passerini reaction (which is analogous to the Ugi reaction) is classically a three component reaction, involving a carboxylic acid, a carbonyl compound and an isocyanide, resulting in the formation of a new amide and ester bond. ${ }^{[18]}$ However, a great deal of effort has been made to explore new starting materials for this MCR. One example was reported by Lingaswamy et al., by replacing the aldehyde by epoxides. Briefly, the catalyst indium(III) chloride (30 mol\%) promotes, more efficiently than other Lewis acids $\left(\mathrm{FeCl}_{3}, \mathrm{RuCl}_{3}\right.$ or $\left.\mathrm{Cul}\right)$, the epoxide rearrangement into the corresponding aldehyde in situ, which further undergoes the Passerini MCR. Starting from aryl or alkyl epoxides, a small library of a-acyloxyamides (11 examples) was generated in very good to excellent yields, under short reaction times, showcasing the versatility of this methodology (Scheme 3). ${ }^{[19]}$ 




Scheme 3: $\mathrm{InCl}_{3}$ applied as catalyst in an epoxide-based Passerini reaction (including insights on the mechanism of the in situ aldehyde formation).

Indium-based MOFs can also be suitable catalysts for the Ugi and Passerini reactions. Monge and co-workers explored several indium polymeric frameworks (inPF) to promote this type of multicomponent reaction (1 example of each), showcasing the importance of the structural features of these heterogenous catalysts in this transformation. In the Passerini reaction involving benzaldehyde, benzoic acid and cyclohexyl isocyanide, a Metal-Organic-Framework (MOF) with the formula $\left[\mathrm{In}_{8}(\mathrm{OH})_{6}(\text { popha })_{6}\left(\mathrm{H}_{2} \mathrm{O}\right)_{4}\right]$ proved to be the most efficient (yield $=89 \%$ and Turn-OverNumber $(\mathrm{TON})=89)\left(\mathrm{H}_{3}\right.$ popha $=$ 5-(4-carboxy-2-nitrophenoxy)isophthalic acid). However, upon applying this MOF to the Ugi reaction between the same three components plus aniline, afforded only traces of the Ugi adduct. By changing to a MOF with the formula [ $\ln$ (popha)(2,2'-bipyridine)] $3 \mathrm{H}_{2} \mathrm{O}$, the yield improved to $92 \%$, with a TON of $92 .{ }^{[20]}$ Recently, the same group explored the influence of the use of different indium salts in the preparation of indium-based MOFs. The best result was observed with the MOF synthesized from indium(III) chloride, with the formula $\left[\mathrm{In}_{2}(\mathrm{btb})_{2} \mathrm{Cl}_{2}\right]^{2-} \cdot\left[\left(\mathrm{CH}_{3}\right)_{2} \mathrm{NH}_{2}\right]_{2}{ }^{2+},\left(\mathrm{H}_{3} \mathrm{btb}=1,3,5\right.$-tris (4-carboxyphenyl)benzene), which was used for the preparation of $5 \mathrm{Ugi}$ adducts in short reaction times and mild conditions. The catalyst shows high recyclability and no catalyst leaching (Scheme 4). Structurally, the presence of open metal sites, combined with Lewis basic sites, is required to synchronize the different substrates and promote a more efficient catalytic process. ${ }^{[21]}$ 

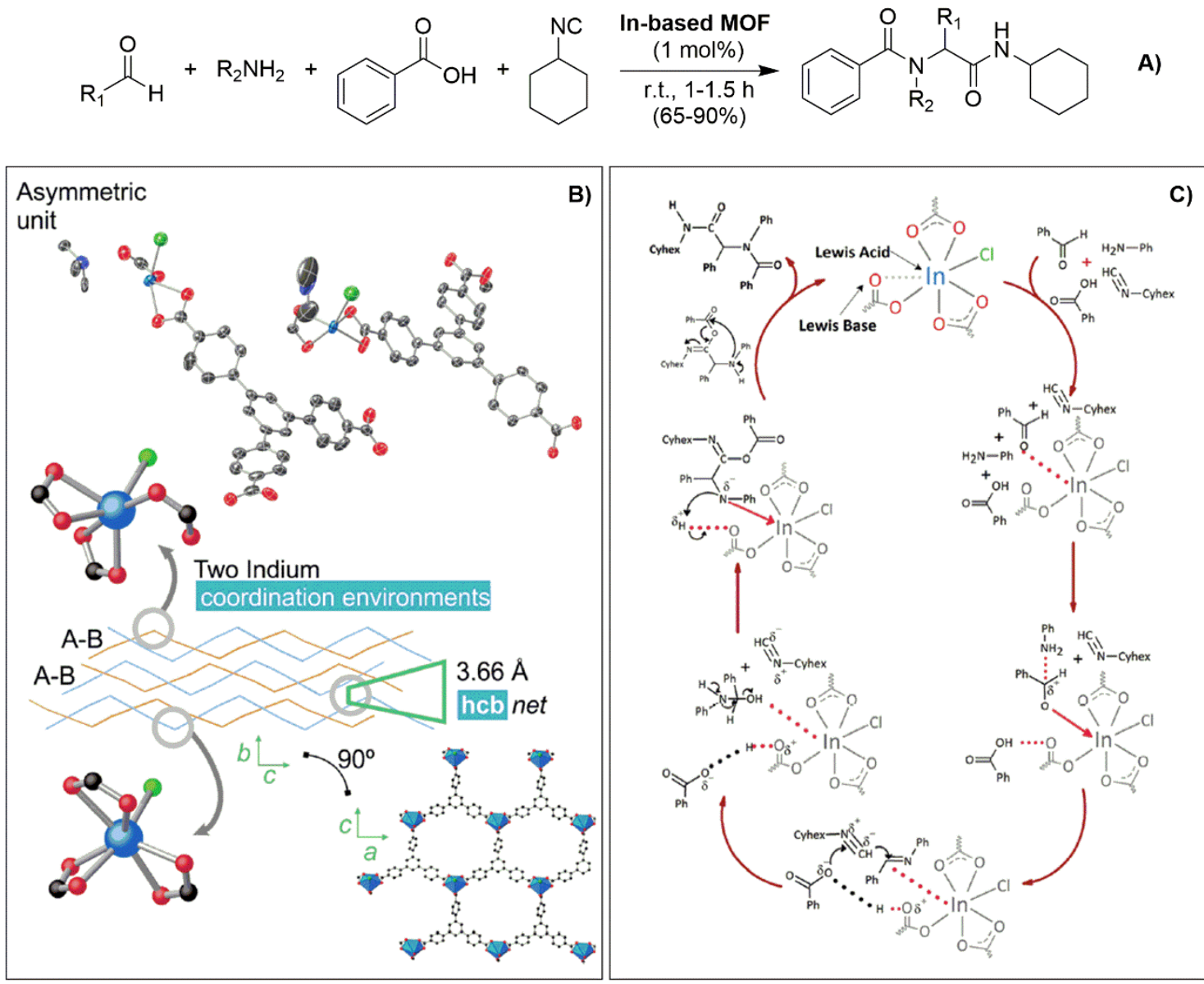

Scheme 4: Indium-based MOF as catalyst for the Ugi reaction (A); Topology and indium coordination environment in the MOF $(B)$; Mechanistic insights of the MOFcatalyzed Ugi reaction (C). B) and C) reproduced from Reinares-Fisac et al., Dalton Trans. 2019, 48, 2988-2995 ${ }^{[21]}$ Copyright (2019), with permission from Royal Society of Chemistry.

Another noteworthy application of indium(III) chloride is the pseudo-five component reaction reported by Tian and co-workers. Briefly, a library of spiro-oxindole derivatives (23 examples) was obtained in moderate to good yields via a multiple isocyanide insertion reaction into various methyleneindolinone derivatives (Scheme 5), which undergo a sequential Michael addition, isocyanide insertion, cyclization and imineenamine tautomerization mechanism. In this case Indium catalyst is involve in two reaction steps, the activation of the carbonyl and the activation of amine in the cyclization step. ${ }^{[22]}$ 

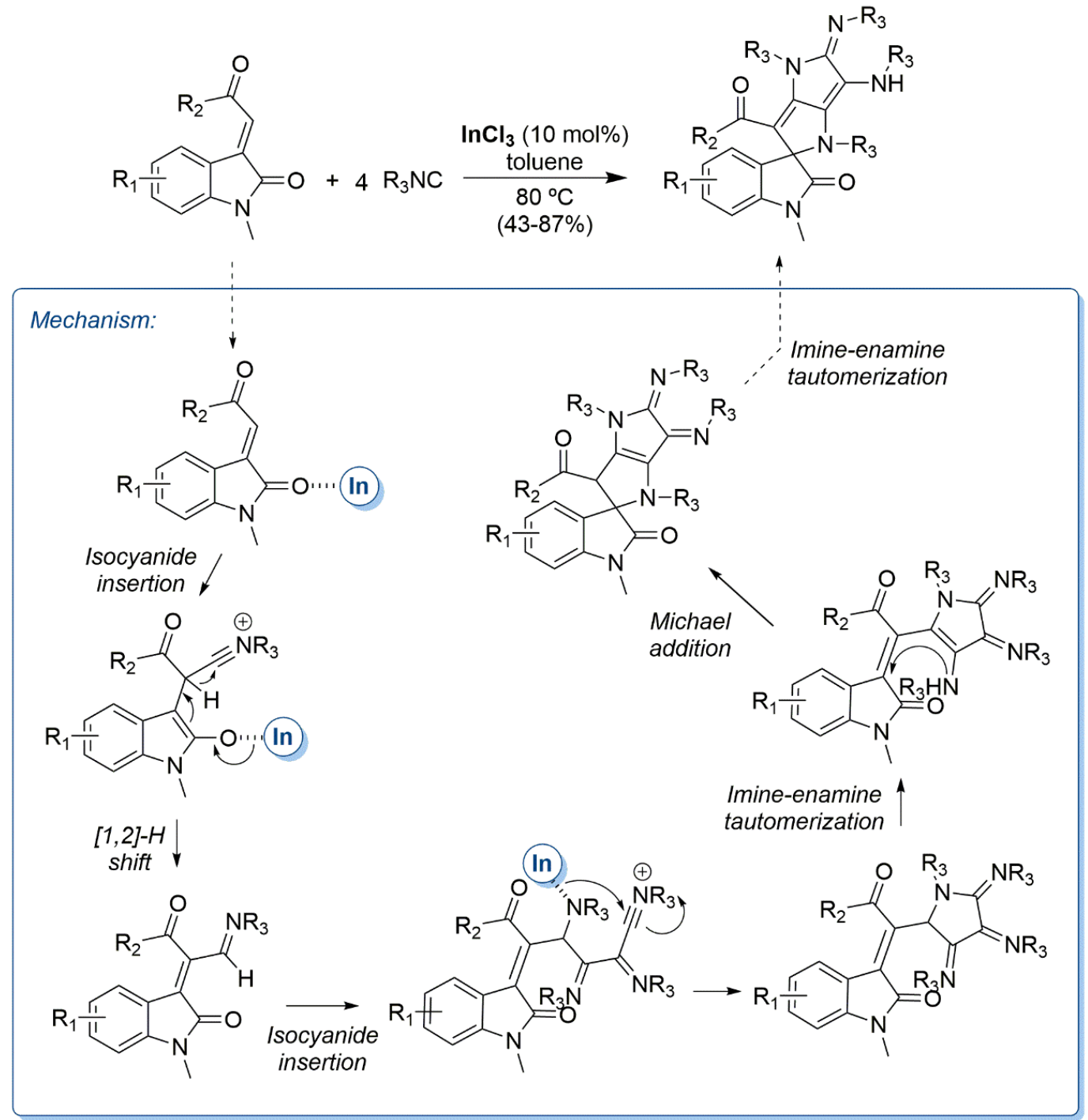

Scheme 5: Multiple isocyanide insertion reaction catalyzed by $\mathrm{InCl}_{3}$.

The GBB reaction is an example of a considerably "young" MCR (a little bit over 20 years old, developed in 1998 simultaneously by K. Groebke, C. Blackburn and H. Bienaymé) with tremendous interest from the medicinal and pharmaceutical chemistry point of view. By promoting the reaction between isocyanides, aldehydes and amines bearing a structural cyclic system $\mathrm{NH}_{2}-\mathrm{C}=\mathrm{N}$, the $\mathrm{GBB}$ reaction allows the preparation of imidazole derivatives, which are a valuable scaffold in drug discovery. ${ }^{[23]}$ The presence of Lewis or Brønsted acids is known to promote this MCR, and therefore various indiumcatalyzed GBB reactions are found in the literature. Among the most recent examples are the ones described by Devi, Singh and co-workers. In one example, the authors explored the synthesis of $\beta$-carboline derivatives via indium triflate catalyzed GBB reaction, obtaining a library of $\beta$-carboline-imidazo[1,2-a]pyridine derivatives (25 examples) and four examples of of $\beta$-carboline-imidazo[1,2-a]pyrazine in good to excellent yields (Scheme 6A). ${ }^{[24]}$ The same catalyst, applied in a lower catalyst loading 
(5 mol\%), was employed by the same group to synthesize tetracyclic structures, consisting of pyrazolopyridinone fused imidazopyridine derivatives (21 examples) in excellent yields (Scheme 6B). In fact, this catalyst proved to be more efficient than other indium salts in this chemical transformation since the application of indium(III) chloride provided slightly lower yields even when the catalyst loading was doubled (10 mol\%). To achieve these interesting frameworks, a one-pot indium catalyzed GBB process, followed by $\mathrm{HBF}_{4}$-promoted dealkylation and respective intramolecular cyclization took place. ${ }^{[25]}$ Swami et al. reported the application of the same indium salt for the synthesis of a wide variety of 3-amino-imidazo[1,2-a]pyridine derivatives (20 examples) in excellent yields (Scheme 6C). This synthetic approach proved to be feasible, simple and suitable for a wide range of starting materials. ${ }^{[26]}$

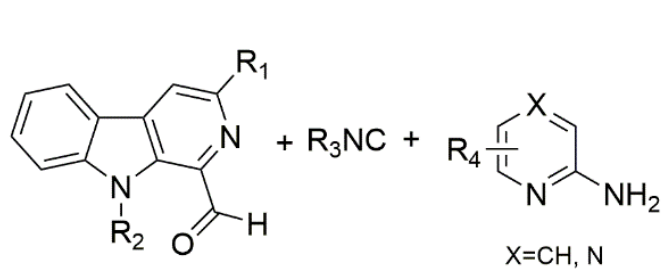

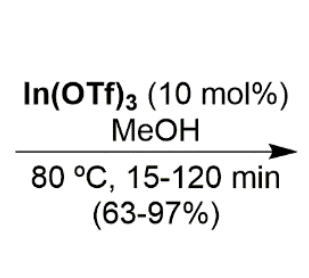<smiles></smiles><smiles>[R][R]1ccc(N)nc1</smiles>

<smiles></smiles>

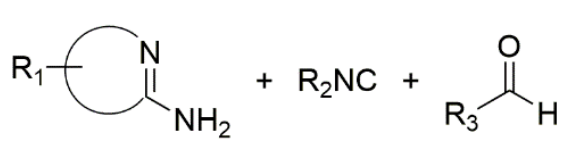

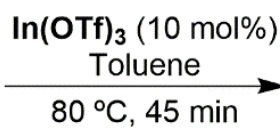
$(83-96 \%)$<smiles>[R7]Nc1c([R3])nc2n1CC[R7]C2</smiles>

C)

Scheme 6: $\ln (\mathrm{OTf})_{3}$-catalyzed GBB reactions.

\section{2. $A^{3}$-Coupling reactions}

The MCR denominated $\mathrm{A}^{3}$-coupling consists of the reaction between an aldehyde, an alkyne and an amine, catalyzed by a transition metal, to afford propargylamines (Scheme 7). The synthetic relevance of these compounds is remarkable, and they are often used as key synthetic intermediates in the preparation of nitrogen-containing heterocycles, natural alkaloids, bioactive molecules and active pharmaceutical ingredients (APIs), such as the anxiolytic drugs zolpidem and alpidem. In recent years, several efforts were made in order to explore further substrates for this chemical transformation, as well as to explore new catalytic systems. ${ }^{[27]}$ 




Scheme 7: Mechanistic insights of the $A^{3}$-coupling reaction.

As a post-transition metal, indium emerges as a suitable candidate for $A^{3}$-coupling catalysis. Among the most recent efforts in this field, the example reported by Lima da Silva et al. concerning the preparation of propargylamines under solvent-free and heterogeneous catalysis conditions deserves particular attention. The catalyst, consisting of recyclable silica-xerogel-supported indium(III) composite ( $\left.\mathrm{In} / \mathrm{SiO}_{2}\right)$, proved to be efficient in this solvent-free chemical transformation, under conventional heating and MAOS (with the later allowing a considerable time reduction from 12 hours to 10 minutes) affording the desired propargylamines (9 examples) in good to excellent yields (Scheme 8A). ${ }^{[28]}$ In a different example, indium(III) tribromide was used as catalyst for the preparation of a small library of imidazo[1,2-a]pyridine derivatives (16 examples) in good to very good yields (the lowest yield was observed when using an aliphatic aldehyde) (Scheme 8B). Mechanistically, the synthetic process undergoes a consecutive $\mathrm{A}^{3}$-coupling and cycloisomerization, with the nitrogen atom of the 2 aminopyridine working as an extra nucleophile and allowing the preparation of the bicyclic structure. ${ }^{[29]}$ Sarmah et al. reported the synthesis of a library of benzo[ $h]$ quinolines (16 examples) under MAOS and solvent-free conditions. The catalyst used was indium triflate and the desired tricyclic structures were obtained in very good to excellent yields with short reaction times (Scheme $\mathbf{8 C}$ ). The authors reported this synthetic process to occur via a imino-Diels-Alder mechanism. ${ }^{[30]}$ However, the combination of mechanistic studies, observation of the structural similarity of the reactants, combined with examples reported in the literature of quinoline derivatives using the $A^{3}$-coupling $M C R,{ }^{[27 a]}$ suggested that this reaction occurred via sequential $A^{3}$ - 
coupling/cycloisomerization/oxidation cascade, with the formation of a propargylamine intermediate.
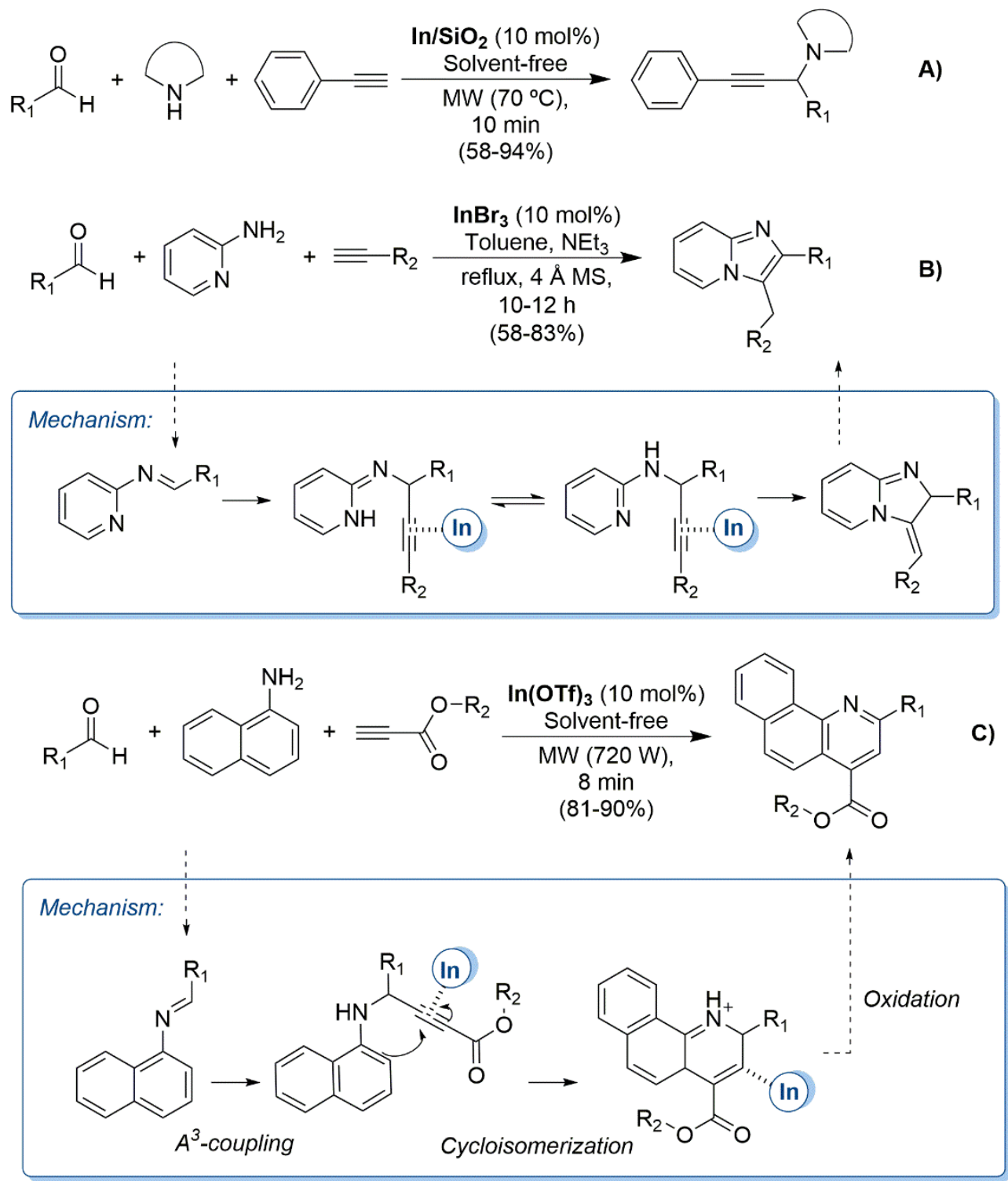

Scheme 8: Examples of indium catalyzed $\mathrm{A}^{3}$-coupling reactions.

The use of alternative starting materials for the $A^{3}$-coupling is relevant to further expand the scope of this MCR. Das et al. reported the synthesis of quinoline derivatives (17 examples), in the presence of indium (excess) in diluted hydrochloric acid, replacing the amine reactant by a nitroarene moiety (Scheme 9A). This approach allowed the preparation of indium(III) chloride in situ, from metallic indium and aqueous hydrochloric acid. The nitro group is reduced in situ, generating the corresponding aniline, which further undergoes the already described coupling/cycloisomerization/oxidation process, allowing the preparation of the desired derivatives in overall very good yields. ${ }^{\left[{ }^{11}\right]}$ In another example, propargylamines (25 examples) were prepared from dibenzylamine, different alkynes and acetals, in replacement of aldehydes (Scheme 9B). Acyclic and 
cyclic acetals were deprotected in situ to the corresponding aldehydes by indium(III) chloride, which further catalyzed a typical $A^{3}$-coupling, affording the final propargylamines in overall very good yields (lower yields were observed when using cyclic acetals or strongly withdrawing substituents, such as $p$-nitro group). ${ }^{[32]}$

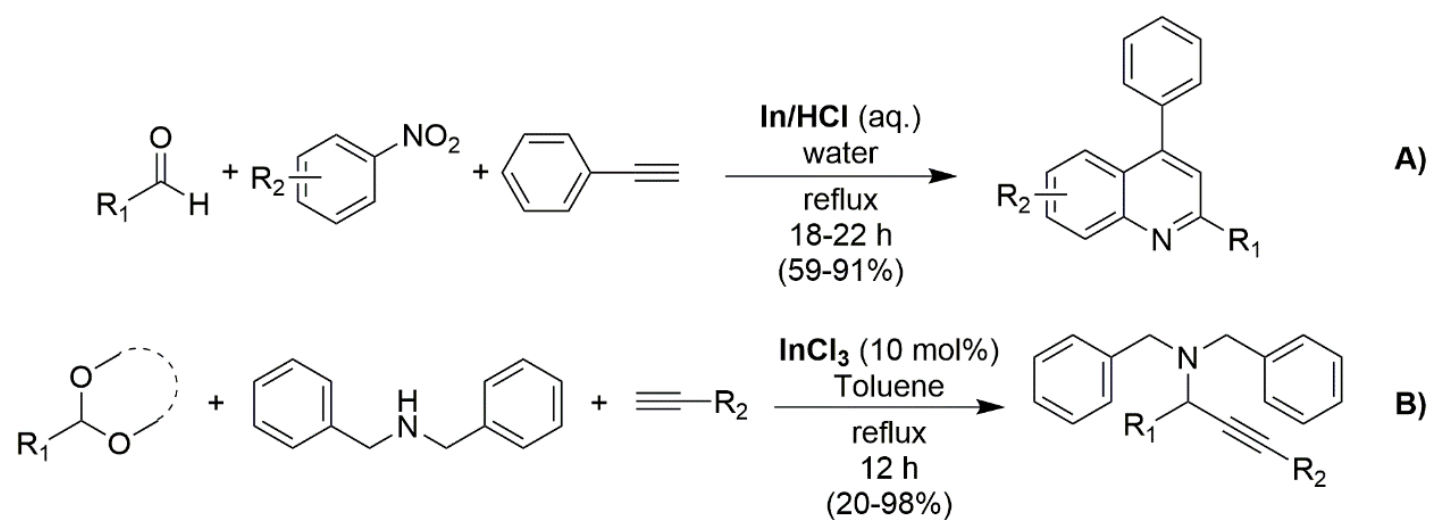

Scheme 9: $\mathrm{A}^{3}$-coupling reactions using unconventional starting materials.

\section{Knoevenagel-initiated MCRs}

Although not being a multicomponent reaction per se, the Knoevenagel reaction is often the first mechanistic step of various cascade-based multicomponent approaches, especially combined with the Michael addition. ${ }^{[33]}$ Catalytic versions of these chemical transformations are very popular, with several examples reporting the use of indium salts to promote these multicomponent synthetic processes, namely indium(III) chloride.

Lakshmi and co-workers explored the application of this catalyst several times, to obtain 2-amino-4H-chromene derivatives in a multicomponent approach. To achieve these compounds, different salicylaldehydes and malononitrile were combined, under mild reaction conditions, with different cyclic nucleophiles, including 3-methyl-1-phenyl$1 H$-pyrazol-5(4H)-one (Scheme 10A), oxindole (Scheme 10B), 5,5dimethylcyclohexan-1,3-dione (Scheme 10C), rhodanine (Scheme 10D), indane-1,3dione (Scheme 10E) and 4-hydroxycoumarin (Scheme 10F). The corresponding libraries of 2-amino-4-pyrazol-4-yl-4H-chromenes (8 examples), 2-amino-4-(2oxoindolin-3-yl)-4H-chromenes (8 examples), 2-amino-4-(4,4-dimethyl-2,6dioxocyclohexyl)-4H-chromenes (8 examples), 2-amino-4-(4-oxo-2-thioxo-thiazolidin-5yl)-4H-chromenes (8 examples), 2-amino-4-(1,3-dioxo-indan-2-yl)-4H-chromenes (8 examples) and 2-amino-4-(4-hydroxy-2-oxo-2H-chromen-3-yl)-4H-chromenes (8 examples) were prepared with overall very good yields, showcasing the versatility of this synthetic methodology. Mechanistically, salicylaldehyde undergoes Knoevenagel condensation with malononitrile, generating an iminocoumarin intermediate, which further undergoes Michael addition with the cyclic nucleophile to afford the final chromene derivatives. ${ }^{[34]}$ 
A different methodology was reported by Samai et al., consisting in a fourcomponent approach to obtain $4 H$-benzo[f]chromene derivatives (19 examples). To achieve these structures, catalytic amounts of indium(III) chloride promoted the reaction between aromatic aldehydes, $\beta$-naphtol, $\beta$-oxodithioesters and primary alcohols (methanol, ethanol and $n$-butanol; isopropanol did not allow the reaction to occur), with the latter one playing a dual role as reactant and solvent (Scheme 10G). Although mechanistic studies were not performed in detail, the authors hypothesize that the chemical transformation would proceed via Knoevenagel condensation, followed by Michael addition, both of these steps facilitated by the catalyst, followed by intramolecular cyclodehydration and transesterification, to afford the desired chromene derivatives in good yields. ${ }^{[35]}$ 


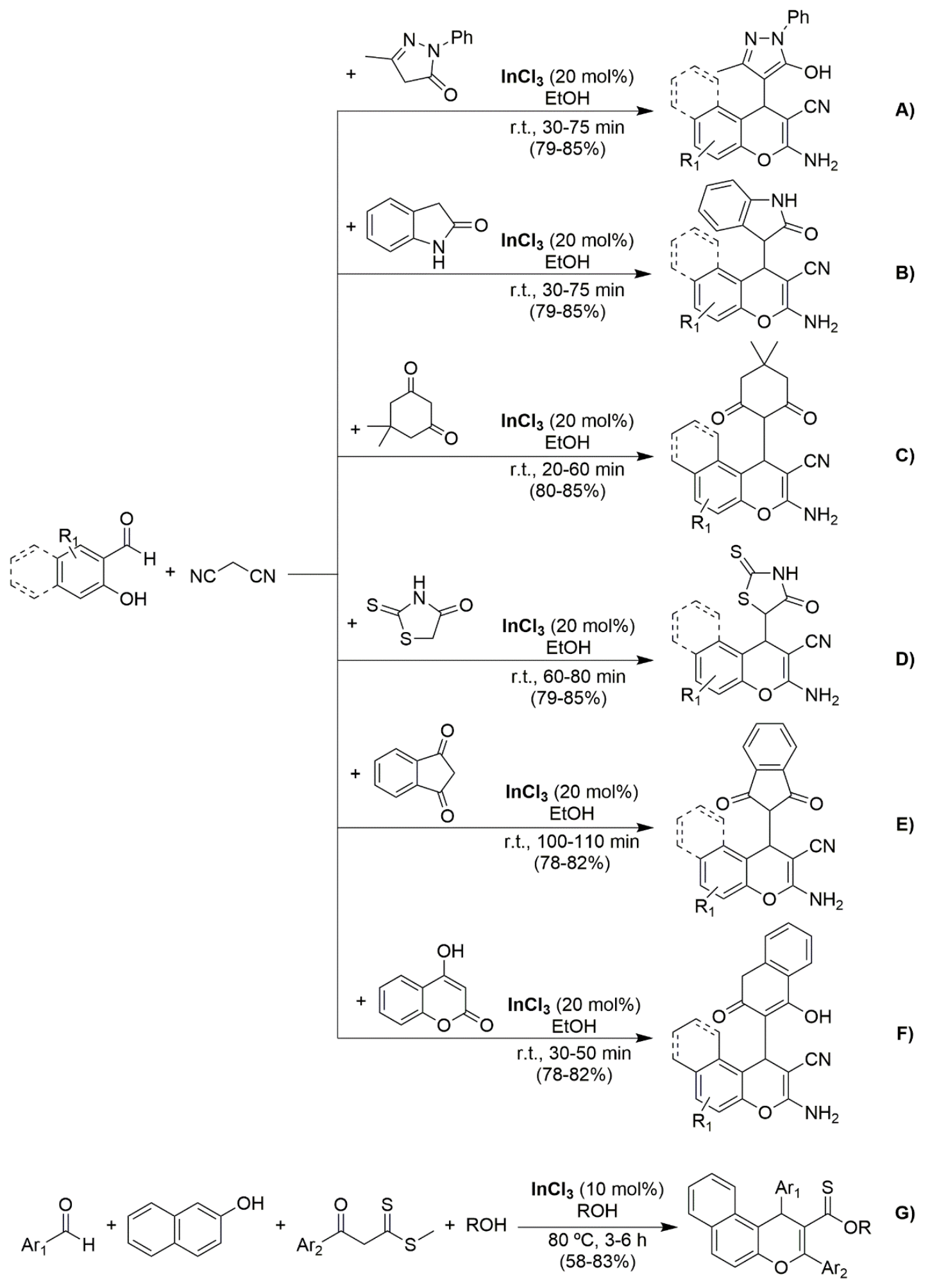

Scheme 10: $\operatorname{lnCl}_{3}$-catalyzed multicomponent reactions initiated with a Knoevenagel condensation to afford chromene derivatives.

The combination of Knoevenagel reaction and Michael addition in multicomponent approaches allow the preparation of several other scaffolds. Dongare et al. explored the use of indium(III) chloride as a catalyst for the preparation of fused 7-azaindole 
derivatives, through the reaction of aromatic aldehydes, 5-amino-1-tert-butyl- $1 \mathrm{H}$-pyrrole3-carbonitrile and dimedone (Scheme 11A - 11 examples) or indane-1,3-dione (Scheme 11B - 9 examples). In the first case, the MCR leads to the formation of dihydro7 -azaindoles in excellent yields, which can be further aromatized in the presence of the oxidant 4,5-dichloro-3,6-dioxocyclohexa-1,4-diene-1,2-dicarbonitrile (DDQ) in almost quantitative yields. In the second approach, the tetracyclic 7-azaindole derivatives are obtained in one-step in excellent yields. ${ }^{[36]}$ The same indium salt was employed in the multicomponent synthesis of highly functionalized pyranopyrazoles (13 examples), in a high-atom economic and sustainable synthetic process. The final products were obtained in excellent yields through the reaction of different aromatic aldehydes, phenylpyrazolone and nitroketene-N,S-acetal (Scheme 11C). ${ }^{[37]}$ Recently, Jadhav et al. reported the synthesis of $1 \mathrm{H}$-pyrazolo[1,2-b]phthalazine-5,10-diones (8 examples) and $1 H$-pyrazolo[1,2-a]pyridazine-5,8-diones (11 examples) from different benzaldehydes, arylacetonitriles and phthalhydrazide or maleic hydrazide, respectively (Scheme 11D). To produce these libraries, indium(III) chloride was once again used as catalyst, although with a higher catalyst load (20 mol\%) compared to the previous examples, through a methodology that allowed excellent yields in short reaction times, under solvent-free conditions. ${ }^{[38]}$

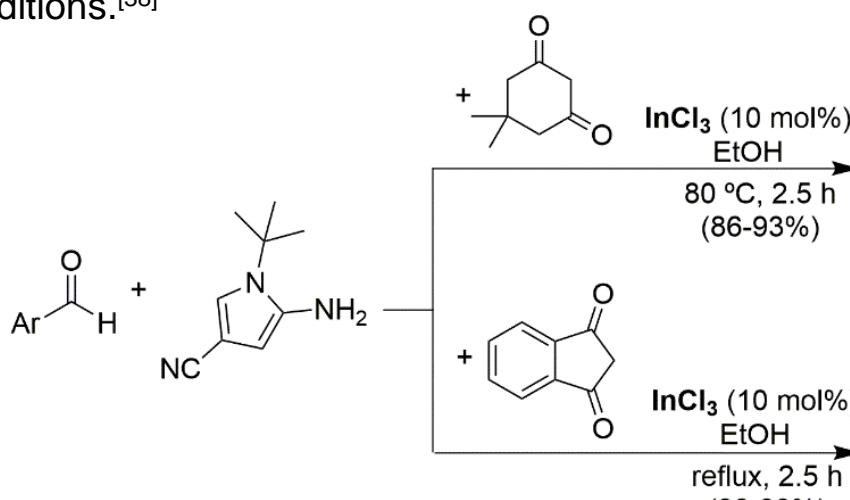

$(86-93 \%)$<smiles>CC1(C)CC(=O)C2=C(C1)Nc1c(c(C#N)cn1C(C)(C)C)C2Br</smiles><smiles>CC1=NN(c2ccccc2)C(=O)C1</smiles><smiles>CNC(=C[N+](=O)[O-])SC</smiles>
$\mathrm{InCl}_{3}(10 \mathrm{~mol} \%)$ $\underset{\text { reflux, 2.5-3 h }}{\mathrm{EtOH} / \mathrm{H}_{2} \mathrm{O}(4: 1)}$ $(86-92 \%)$<smiles>CC(C)(C)n1cc(C#N)c2c(Br)c3c(nc21)-c1ccccc1C3=O</smiles><smiles>[R][R]1ccccc1C1C([N+](=O)[O-])=C(NC)Oc2c(C)nn(-c3ccccc3)c21</smiles>

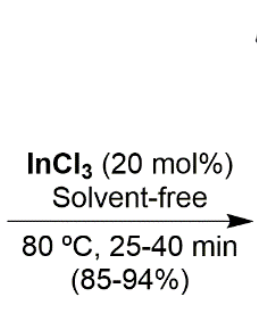<smiles>[R7]c1ccc(C2C(C(=O)c3[R20]ccc3)=C(N)n3c(=O)c4ccccc4c(=O)n32)cc1</smiles>

Scheme 11: $\operatorname{lnCl}_{3}$-catalyzed multicomponent reactions comprising a Knoevenagel condensation and Michael addition. 
In another example, an even higher catalyst load was required to conduct a solvent-free three component reaction between aromatic aldehydes, 2-hydroxy-1,4naphthoquinone and $\beta$-naphtol to obtain a small library of dibenzo[ $a, h]$ anthracene derivatives (11 examples) in variable yields (Scheme 12). The reaction undergoes a Knoevenagel condensation, followed by a Michael addition, intramolecular cyclization and a final dehydration step. ${ }^{[39]}$
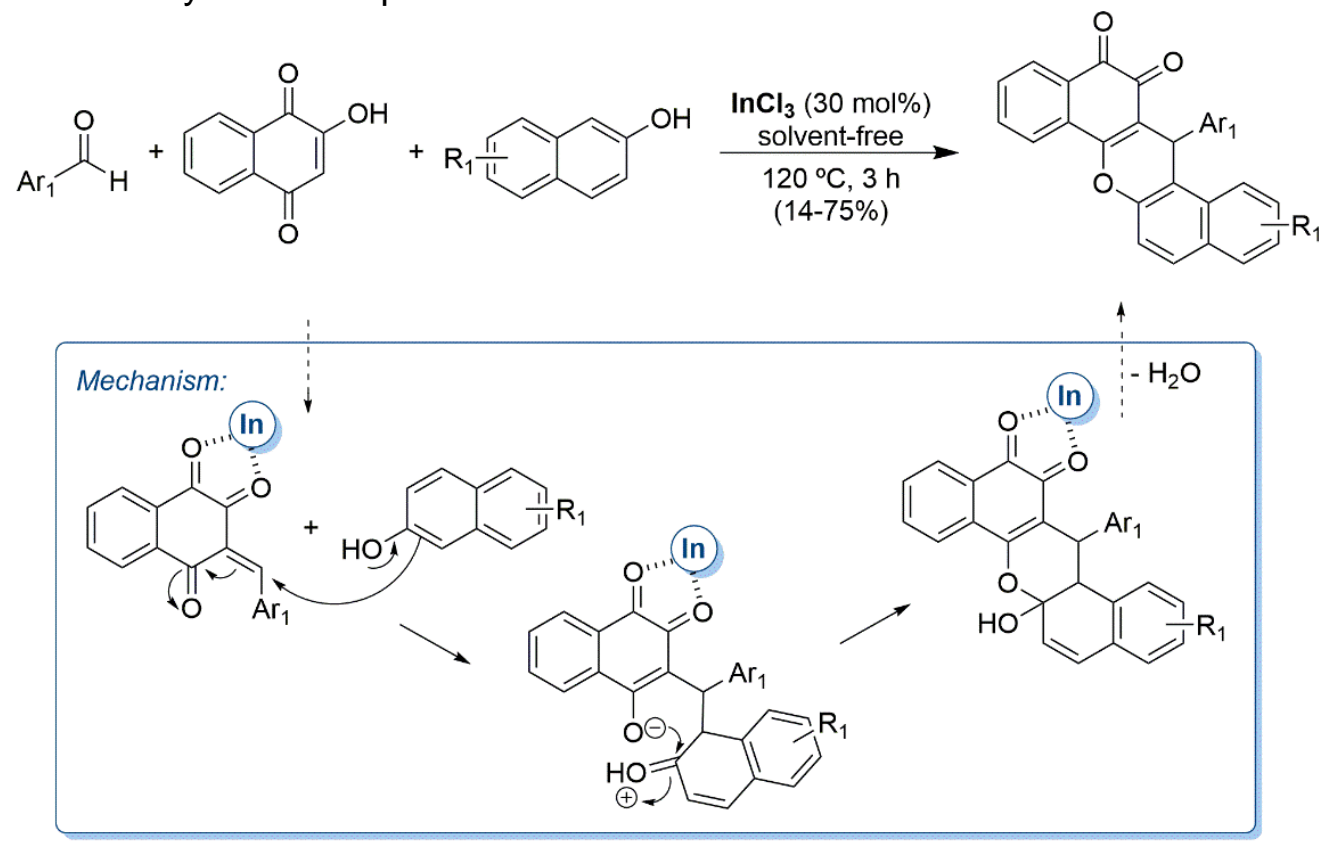

Scheme 12: $\operatorname{lnCl}_{3}$-catalyzed Knoevenagel-initiated ortho-quinonic adducts synthesis.

\section{Hantzsch-type MCR, dihydropyridines and pyrrole synthesis}

The classic Hantzsch reaction was first reported in the $19^{\text {th }}$ century, consisting of the condensation of an aldehyde, two equivalents of a $\beta$-keto ester, and ammonia or ammonium acetate, resulting in a dihydropyridine. ${ }^{[40]}$ Dihydropyridines are very important structures in Medicinal Chemistry, since they are present in several bioactive molecules, including APIs such as nifedipine and felodipine, used in clinical practice for their calcium channel blocking activity. Not surprisingly, several efforts were made throughout the decades to establish alternative synthetic methods to achieve this kind of framework, including other multicomponent approaches. Furthermore, the Hantzsch reaction is continuously revisited, and it is also often applied in the preparation of pyrrole derivatives. ${ }^{[41]}$ For these reasons, in this section, we will address MCRs applied for the synthesis of these relevant frameworks and related structures.

Maiti et al. reported the synthesis of 5,6-disubstituted 1,4-dihydropyridine derivatives (26 examples), via a sequential indium(III) chloride catalyzed four-component reaction involving $\alpha, \beta$-unsaturated aldehydes, $\beta$-ketoesters, aliphatic amines and ethanol (Scheme 13A). The mechanism involves the formation of the corresponding 6-ethoxy- 
1,4,5,6-tetrahydropyridines in situ, which are converted to the final products in very good yields, via ethanol elimination in the presence of neutral alumina and heat. The 5,6disubstituted 1,4-dihydropyridine derivatives can be employed as dienophiles in a wide variety of chemical modifications. ${ }^{[42]}$

Indium triflate, at a higher catalyst loading (20 mol\%), could promote the reaction between carbonyl compounds, two equivalents of malononitrile and acetonitrile, with the latter one working as both substrate and solvent, affording a library of 4-amino-2,3dihydropyridine-3,3,5-tricarbonitriles (Scheme 13B - 10 examples). The catalytic system also required the presence of triflic acid and triethylamine, in order to afford the desired products in very good yields, through a condensation-addition reaction. These compounds could be efficiently converted to the corresponding 3,5-dicarboxylic acids, pyridines and also reduced in the presence of lithium aluminum hydride. ${ }^{[43]}$

The five-component reaction between benzaldehyde ( 2 equivalents), ethyl acetoacetate and 4-methoxyaniline ( 2 equivalents) to afford a highly functionalized tetrahydropyridine in quantitative yield was explored by Kończyk et al., in a process catalyzed by a system constituted of indium(III) trichloride and [1,1'-binaphthalene]-2,2'diol (BINOL). This Brønsted acid allowed to improve the reaction yield, keeping the metal catalyst loading constant and, at the same time, permitted the reaction to proceed under mild conditions (Scheme 13C). ${ }^{[44]}$

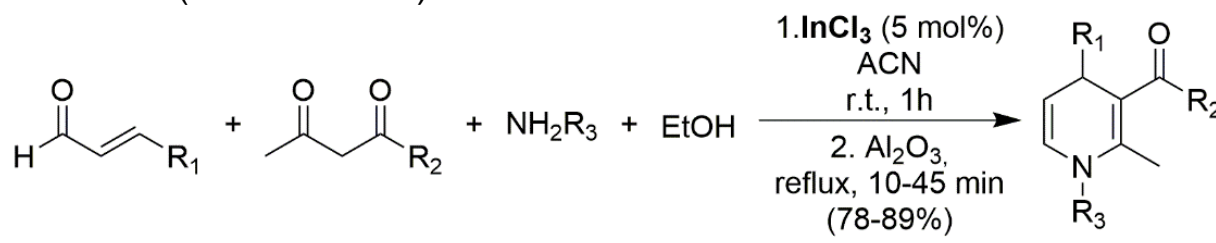

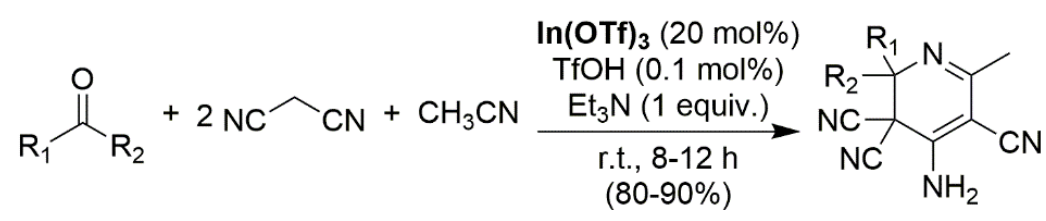

2<smiles>CCOC(=O)CC(C)=O</smiles>

C)

Scheme 13: Indium-catalyzed dihydropyridine synthesis (A and $B)$ and a tetrahydropyridine $(C)$ synthesis via MCRs. 
Concerning the pyrrole derivatives synthesis, a couple of indium-catalyzed examples can be found in the recent literature. Cores et al. reported a Hantzsch-type reaction between primary amines, $\beta$-dicarbonyl compounds and $\alpha$-bromoesters in short reaction times and low catalyst loading (Scheme 14A). The obtained 2-pyrrolin-5-ones (16 examples) were prepared through the formation of a $\beta$-enamino ester intermediate, which further reacts with the $\alpha$-bromoester, which through a tautomerization/cyclization process, allows the formation of the final products in moderate to good yields. ${ }^{[45]}$

A library of polysubstituted pyrroles (12 examples) was prepared via MCR between phenacyl bromide (or its derivatives), dialkyl acetylene dicarboxylates and nitro compounds with very good yields (Scheme 14B). Mechanistically, the acidic condition leadting to the generation of the indium salt allows, at the same time, the reduction of the nitro compound to the corresponding primary amine, which further reacts with the dialkyl acetylene dicarboxylate to generate an intermediate zwitterionic species, which further reacts with the phenacyl bromide, generating another intermediate which undergoes indium(III) chloride catalyzed cyclization and aromatization to afford the final product. ${ }^{[46]}$



A)

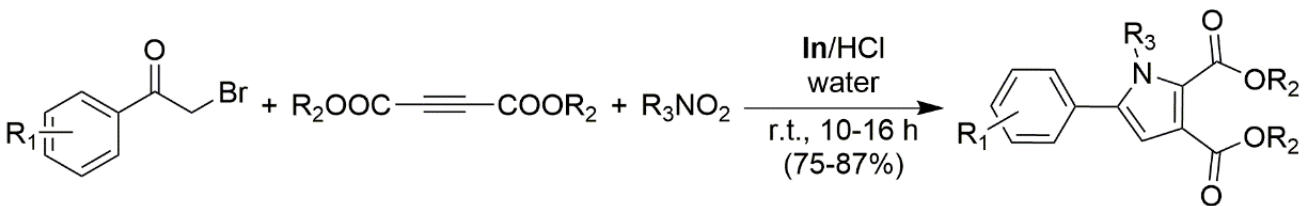

Scheme 14: Indium-catalyzed pyrrole derivatives synthesis via MCRs.

\section{Multi-catalytic systems and nanocatalysis}

The already described in situ formation of indium(III) chloride from indium metal in aqueous hydrochloric acid was also applied by Das et al., while exploring the MCR between nitroarenes, dialkyl acetylene dicarboxylates and formaldehyde (which needs to be present in excess). By changing the number of equivalents of the nitroarene component, researchers could prepare a library of 1,3,3-trisubstituted-4,5dioxopyrrolidines (15 examples - Scheme 15A), when used in a ratio of $1: 1: 4$ and, by duplicating the equivalents of the nitroarene component (2:1:4), a library of $1,3,4,5$ tetrasubstituted-1,2,3,6-tetrahydropyrimidines (10 examples - Scheme 15B) could be synthesized. Both libraries were prepared under mild conditions and short reaction times, leading to the formation of the final products in overall good yields, via the reduction of 
the nitro compounds to the corresponding primary amines, which are then attacked by both formaldehyde and dialkyl acetylene dicarboxylate. ${ }^{[47]}$

In a totally different approach, Tsai et al. employed a indium(III) chloride/silica gel to promote an MCR between hydrazonoyl hydrochloride (3 equivalents) and N,N'bis(trimethylsilyl)carbodiimine (1 equivalent), affording a small library of 5-[2-(1,2,4triazol-3-yl)hydrazinyl]-1,2,4-triazin-6-one derivatives (12 examples), with the yields obtained being highly dependent on the nitrile imine substitution pattern, with the presence of electron-withdrawing groups determining a low yield $\left(p-\mathrm{CN}\right.$ and $p-\mathrm{NO}_{2}, 8 \%$ and trace amount, respectively), electron-donating group ( $p$-OMe) not allowing the reaction to proceed, and the remaining substituents (halogens, $-\mathrm{CF}_{3},-\mathrm{CH}_{3},-\mathrm{H}$ ) allowing moderate yields (>59\%) (Scheme 15C). This complex synthetic approach comprises the generation of a coordination complex formed between the nitrile imine and $\mathrm{InCl}_{3}$, which then undergoes 1,3-dipolar cycloaddition with N,N'-bis(trimethylsilyl)carbodiimine, leading to the formation of a dihydrotriazole cycloadduct. This intermediate then faces desilylation, forming a 1-aryl-5-(trimethylsilylamino)-1 $\mathrm{H}$-1,2,4-triazole intermediate. Meanwhile, a second equivalent of hydrazonoyl hydrochloride generates a nitrile imine zwitterion in the presence of the catalyst, which further undergoes a multicomponent cyclization reaction with a third equivalent of the hydrazonoyl hydrochloride and a silylamide anion generated in situ, affording a 1,2,4-triazin-6-one intermediate. The latter is then purported to combine with 1 -aryl-5-(trimethylsilylamino)-1H-1,2,4-triazole via nucleophilic substitution (which generates the silylamide anion as a leaving group), leading to the formation of the desired product. ${ }^{[48]}$ 


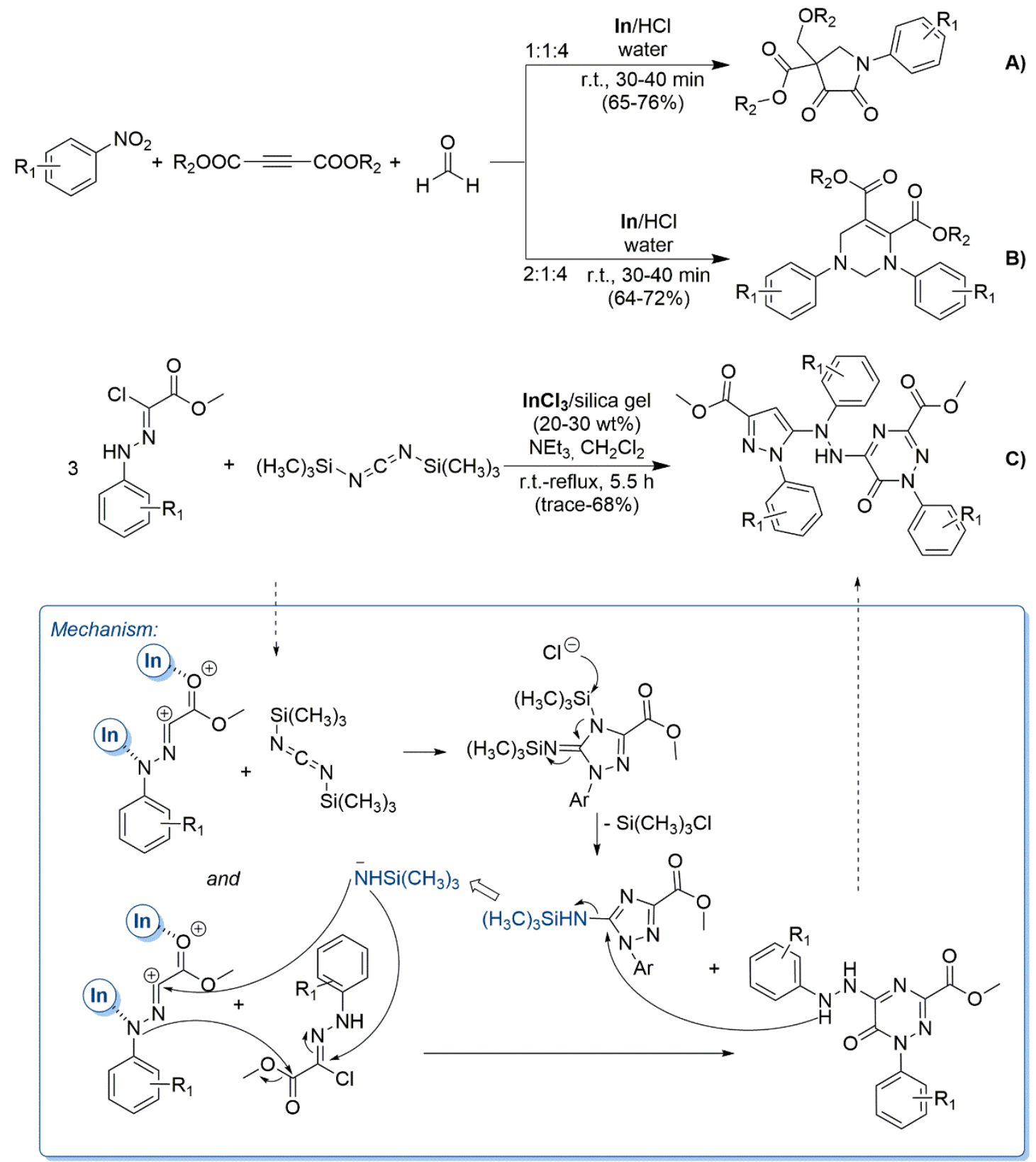

Scheme 15: Multi-catalytic systems comprising indium in the synthesis of polysubstituted heterocycles.

Dual catalytic systems involving two metal catalysts are also important improvements for the development of new and more efficient synthetic methodologies. The combination of indium(III) chloride and zinc has proven to be efficient in the fivecomponent synthetic approach to obtain 1,4-diazepine derivatives (10 examples) under mild and sustainable reaction conditions (Scheme 16A). This highly diastereoselective process, leading to the favorable formation of the trans isomer (95-97\%), is mostly driven by steric hindrance of vicinal aryl groups. Mechanistically, the synthetic process occurs via a tandem imino-pinacol coupling-aza-Michael reaction, which includes in situ aldimine formation and a bimolecular reductive coupling to afford $N, N$ '-diphenyl-1,2- 
diaryl-1,2-diamino ethane. This intermediate undergoes aza-Michael addition with an $\alpha, \beta$-unsaturated ketone, which through dehydrative cycloaddition affords the corresponding diazepine derivative in very good yields. ${ }^{[49]}$

The synthesis of several 3,4-diester-substituted $\mathrm{N}$-arylpyrazole derivatives (27 examples) was recently reported, via an indium and silver dual catalytic approach. To achieve such a goal, a three component reaction was undertaken involving arylhydrazine hydrochlorides and two equivalents of $\beta$-enamino esters (Scheme 16B), through a $[2+2+1]$-oxidative $\mathrm{N}$-annulation, which proceeds via a cascade triple Michael addition/elimination/oxidation, allowing the preparation of these valuable $\mathrm{N}$-arylpyrazole derivatives. ${ }^{[50]}$ 

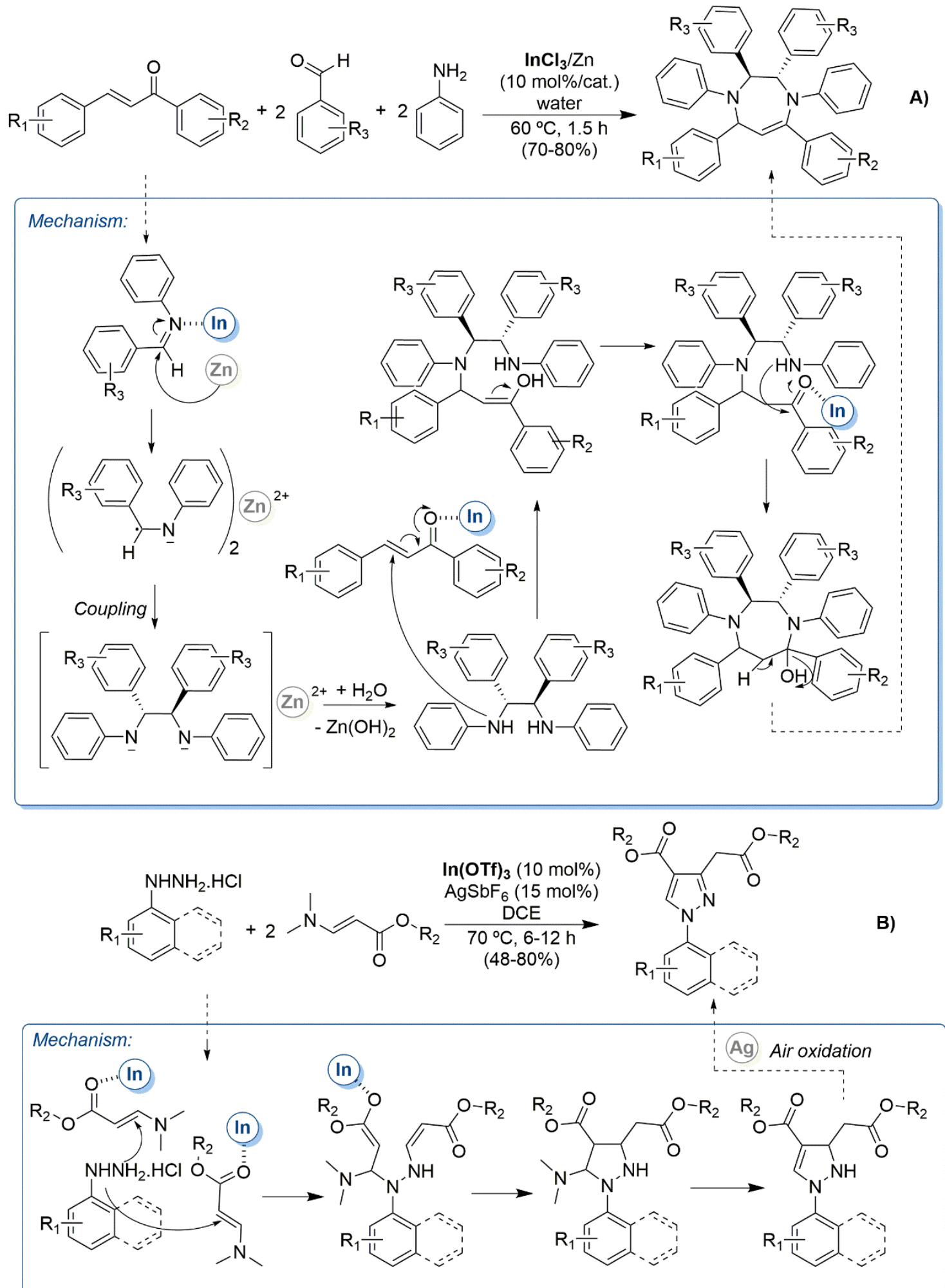

Scheme 16: Examples of dual-metal catalysis in MCR involving indium (DCE=1,2-dichloroethane).

The use of nanoparticles (NPs) as catalysts is a growing research field, and indium catalysis is no exception to this trend. In recent years, a couple of examples reporting the use of indium oxide NPs as catalysts has showcased the versatility of this kind of 
catalyst. Patil et al. reported the synthesis of amidoalkyl naphtol derivatives (20 examples) via a multicomponent reaction between $\beta$-naphtol, aldehydes and acetamides or urea, in short reaction times using these NPs (Scheme 17A). Excellent yields were obtained (> 85\%) when benzaldehydes were employed in the reaction, whereas aliphatic aldehydes allowed slightly lower yields (62-70\%). Mechanistically, the reaction between the aldehyde and $\beta$-naphtol affords an ortho-quinone methide intermediate, which by conjugate addition of the acetamide/urea affords the final product. The structure of the nanoparticles was indeed relevant for the catalytic activity, since amorphous indium oxide particles were also evaluated, leading to considerably lower yields $(<50 \%)$ even at longer reaction times. ${ }^{[51]}$ The same type of NPs, at the same catalyst load, was also employed in the three component reaction between isatoic anhydride, benzaldehydes and anilines (Scheme 17B) or ammonium salts (Scheme 17C). This approach led to the preparation of two libraries of 2,3-dihydroquinazolin-4(1H)-ones (15 and 6 examples, respectively) in very good yields and sustainable conditions, since a mixture of water and ethanol could be applied as the reaction media and the heterogeneous catalyst could also be successfully recycled (Scheme 17D), demonstrating once again the importance of using this type of NPs in catalysis. ${ }^{[52]}$ 




A)

Synthetic intermediate
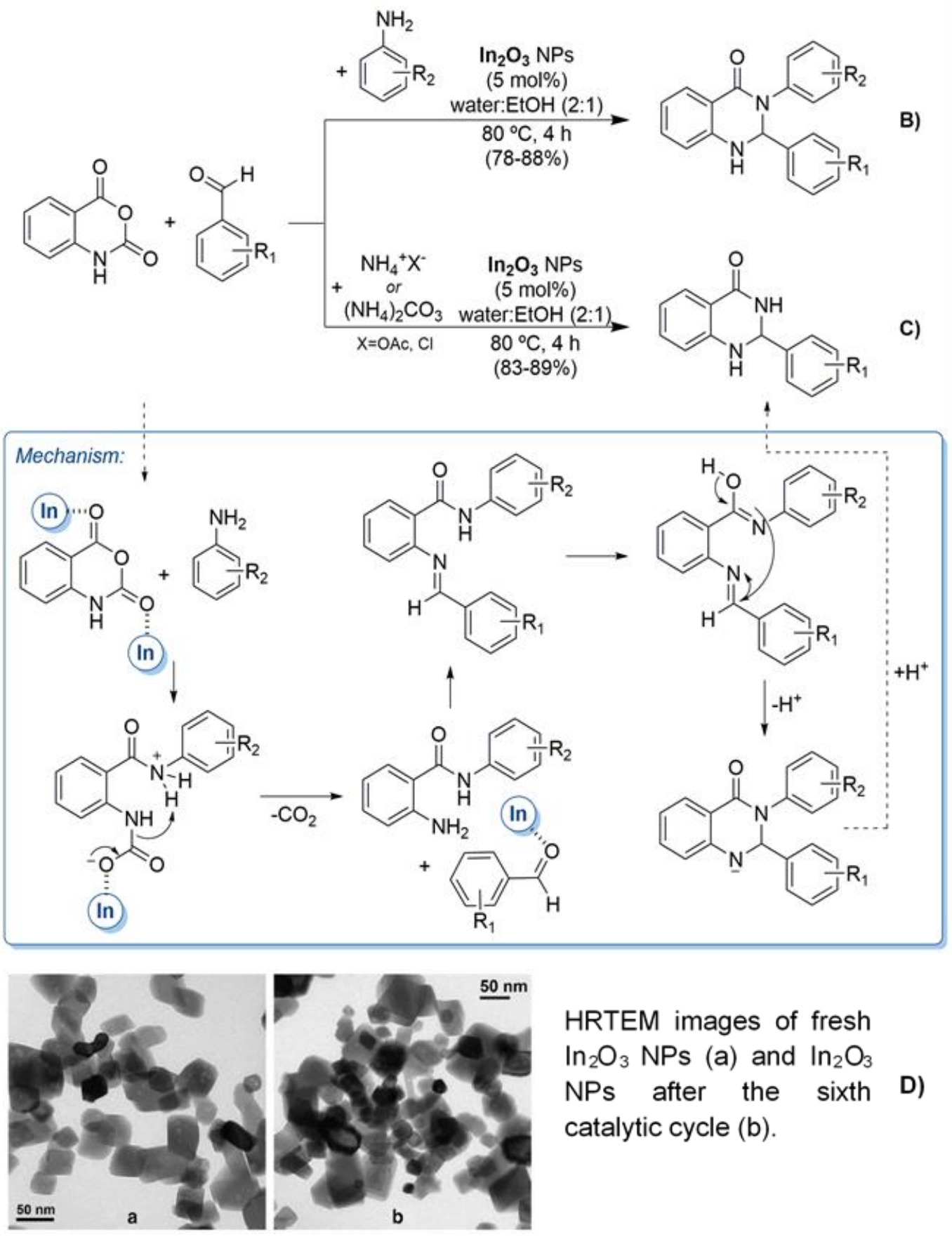

HRTEM images of fresh $\mathrm{In}_{2} \mathrm{O}_{3} \mathrm{NPs}(\mathrm{a})$ and $\ln _{2} \mathrm{O}_{3}$ NPs after the sixth D) catalytic cycle (b).

Scheme 17: Indium oxide NPs mediated MCR. D) reproduced from Santra et al., Catal. Commun. 2014, 49, 52-57[52] Copyright (2014), with permission from Elsevier. 


\section{Miscellaneous}

In this section we address examples of reactions which are seldom reported in the literature, organized according to the indium source applied as catalyst, as well as the chemical framework obtained.

As was observed in most of the sections of this work, indium(III) chloride is the most commonly reported indium salt catalyst and has proven to be suitable to prepare a wide variety of chemical scaffolds. As a matter of fact, the already described reaction to obtain 2,3-dihydroquinazolin-4(1H)-ones using indium oxide NPs (Scheme 17C) was recently explored by Sahu et al., using indium(III) as the catalyst (Scheme 18). The generated library (10 examples) was prepared in excellent yields and in slightly shorter reaction times. ${ }^{[53]}$

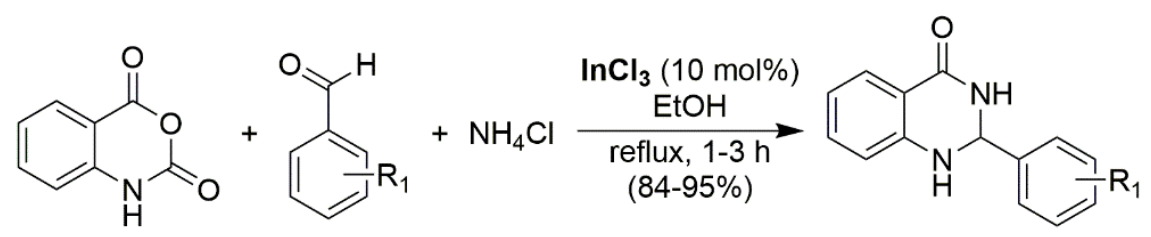

Scheme 18: $\operatorname{lnCl}_{3}$-catalyzed 2,3-dihydroquinazolin-4(1H)-one synthesis.

The same catalyst at a higher loading was applied in the synthesis of fluorescent hydroxyl naphthalene-1,4-dione derivatives (26 examples) via a three-component reaction involving benzaldehydes, 2-hydroxy-1,4-naphthoquinone and anilines or heterocyclic primary amines (Scheme 19A). The reaction allowed the preparation of these derivatives in refluxing water with very good yields. ${ }^{[54]}$ Nandi et al. reported a solvent-free method with a higher catalyst loading used for the synthesis of naphthopyranopyrimidines (18 examples), using different benzaldehydes, $\beta$-naphtol and 6-amino-1,3-dimethyluracil as starting materials (Scheme 19B). This highly atomeconomic process, which releases only water and ammonia as side-products, could afford the desired products in good overall yields. ${ }^{[55]}$ 


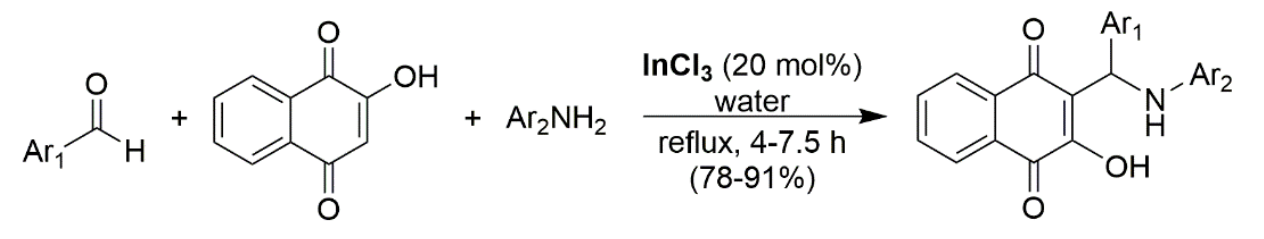

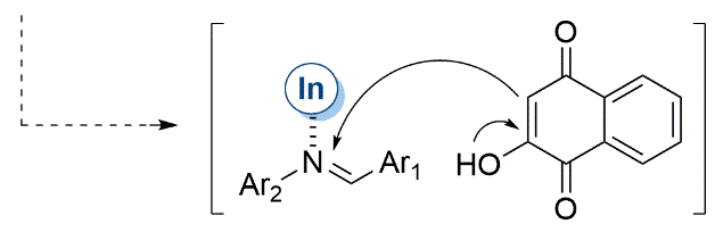

Key-step<smiles>Cn1c2c(c(=O)n(C)c1=O)C([14CH3])c1c(ccc3ccccc13)O2</smiles>

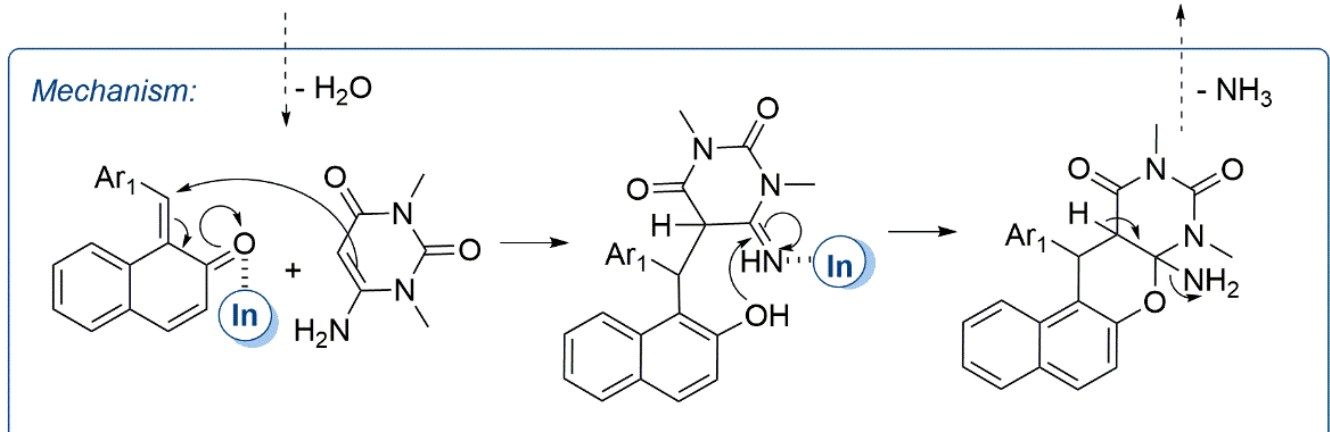

Scheme 19: $\mathrm{InCl}_{3}$-catalyzed synthesis of hydroxyl naphthalene-1,4-diones $(\mathrm{A})$ and naphthopyranopyrimidines (B).

The next set of examples comprise MCRs which led to the formation of imidazole derivatives, which are very important structures in the field of Medicinal Chemistry. ${ }^{[56]}$ First, the synthesis of chromenone- and quinolone-annulated imidazole derivatives (13 examples) via a three component reaction was reported by Majumdar et al., using aromatic aldehydes, sodium azide and the appropriate bicyclic compound as starting materials (Scheme 20A). This synthetic methodology has proven to be very efficient in obtaining the desired chromeno[5,6- $d$ ]imidazol-7(3H)-one and 3,6-dihydro-7Himidazo[4,5-f]quinolin-7-one in very good yields, through the formation of an imine between the amine group of the bicyclic compound and the aldehyde, followed by azide insertion (which can occur directly or by halogen replacement), cyclization and aromatization to form the final products. ${ }^{[57]}$

Other two examples comprise four component reactions involving a-diketones, ammonium acetate, aldehydes, and amines, although the final products are structurally quite different, due to the substitution pattern/functionalization of the last two components. Nhguyen et al. explored the synthesis of polysubstituted $9 \mathrm{H}$ - 
benzo[f]imidazo[1,2- $d][1,2,3]$ triazolo[1,5-a][1,4]diazepine derivatives (14 examples), using o-azido-benzaldehydes and propargylic amines (Scheme 20B). This synthetic approach undergoes an initial formation of an imine between the aldehyde and the ammonia, followed by nucleophilic addition of propargylamine. The resulting intermediate proceeds to form the imidazole and triazole rings, with the latter being formed via intramolecular azide-alkyne 1,3-dipolar cycloaddition. ${ }^{[58]}$ In the second example, the aldehyde used was formaldehyde, and the primary amine consisted of $C$ glycosyl methylamines (with the sugar consisting of $C-\beta-D$-glucopyranosyl or $C-\beta-D$ galactopyranosyl units). This chemical transformation, which proceeded under mild conditions, allowed the preparation of 1 -glycosylmethyl-1H-imidazole derivatives (12 examples) in variable yields (Scheme 20C) (but the yields were higher when a-diketones with $\mathrm{R}_{1}=\mathrm{R}_{2}$ were used as compared to unsymmetrical ones).

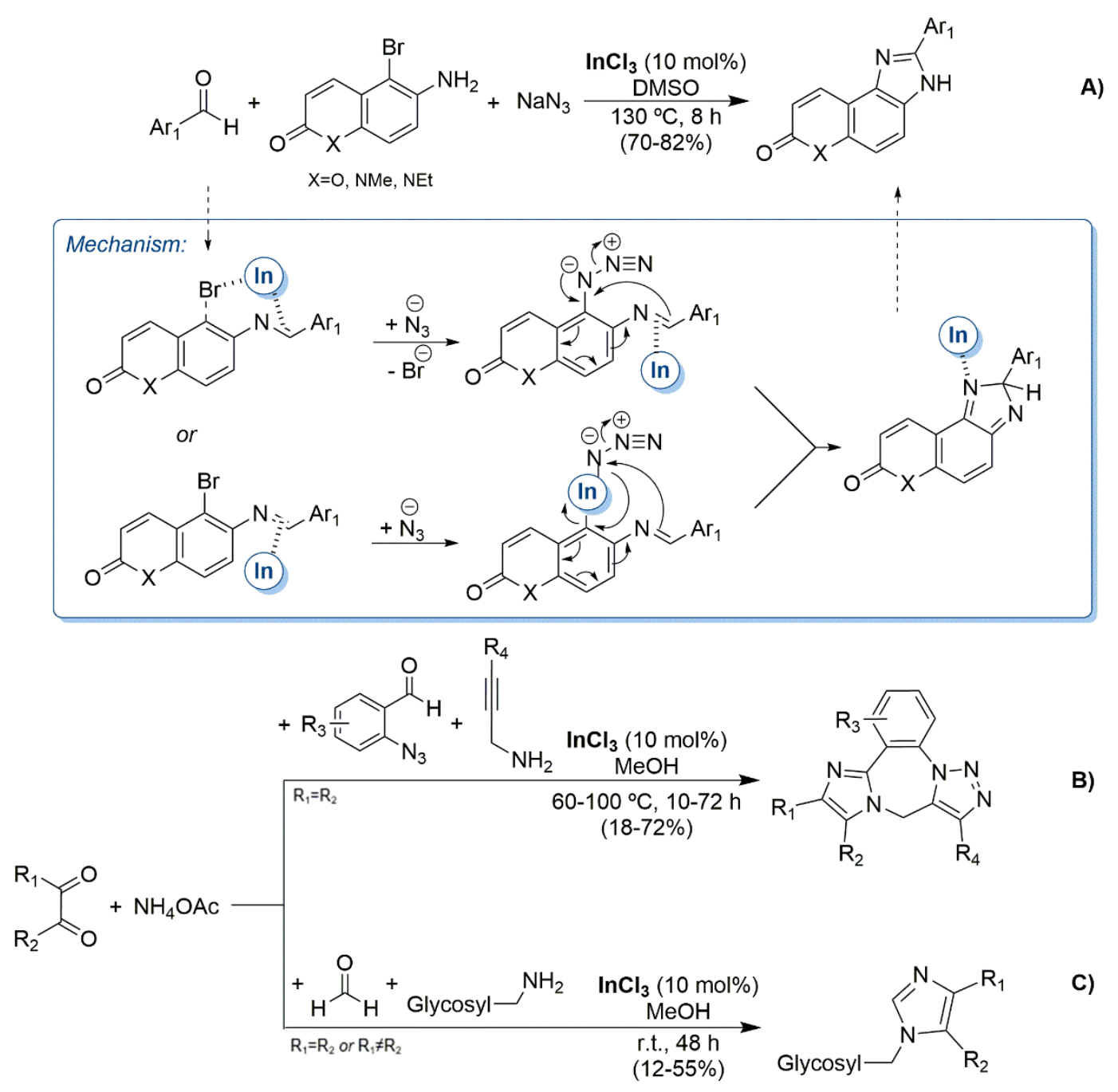

Scheme 20: $\operatorname{lnCl}_{3}$-catalyzed imidazole derivative synthesis.

The indium(III) chloride catalyzed three component reaction between 4methylcoumarins, isatins and hydrazine under microwave irradiation was explored by 
Siddiqui et al.. These synthetic processes, undertaken with short reaction times, allow the preparation of oxindole-4-methyl-1H-quinolin-2-one derivatives (12 examples) in excellent yields, via a dehydrative nucleophilic substitution on the coumarin heterocycle by the in situ formed isatin hydrazone (Scheme 21). ${ }^{[59]}$

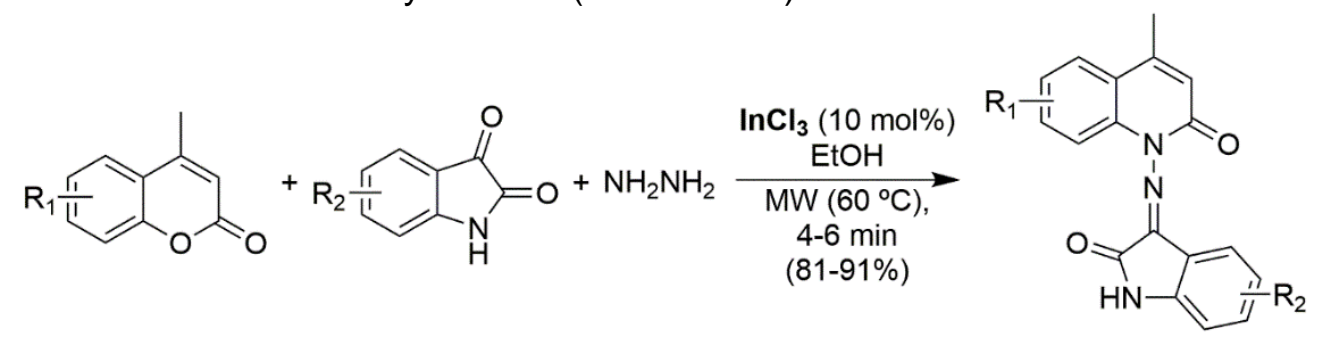

Scheme 21: $\operatorname{lnCl}_{3}$-catalyzed oxindole-quinolin-2-one derivatives.

The same indium salt was applied in the catalytic synthesis of 1 -aminocarbazole derivatives (8 examples) using 2-acetyl-1H-indole, an alkyne and cyclic secondary amines as starting materials (Scheme 22). This MCR involved essentially a C-3 alkylation of the indole moiety with the alkyne, followed by enamine formation and finally a 6-exo-dig cyclization/aromatization step to afford the final products in moderate to good yields. ${ }^{[60]}$

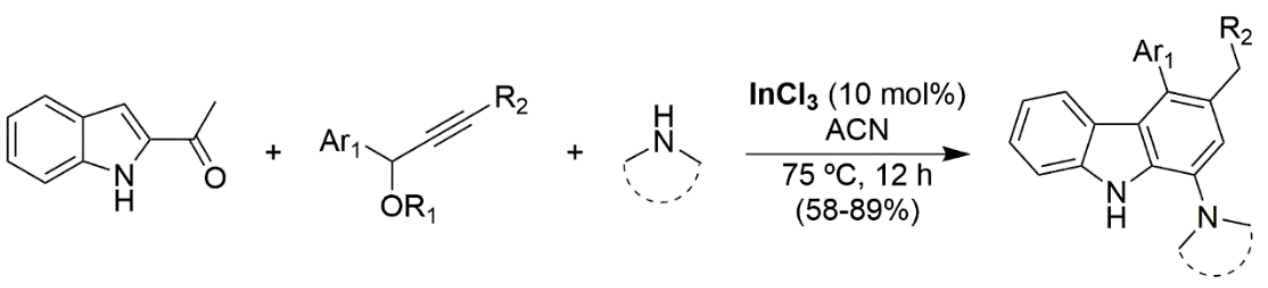

Scheme 22: $\operatorname{lnCl}_{3}$-catalyzed aminocarbazole derivatives.

While exploring the reactivity of $\mathrm{N}, \mathrm{N}$-dimethylhydrazone, Menéndez and coworkers developed a three component reaction involving this compound, anilines and benzaldehydes (Scheme 23). Employing indium(III) chloride as catalyst, this reaction allowed the preparation of 1,2,3,4-tetrahydroquinolines (16 examples) under mild conditions as the major product in almost every case. However, two other derivatives could also be isolated, namely the uncommon 1,2,3,3a,4,8b-hexahydropyrrolo[3,2$b]$ indole derivatives and the undesired transimination product, particularly when electronwithdrawing substituents were present. ${ }^{[61]}$ 1,2,3,4-Tetrahydroquinoline derivatives have also been prepared in a two-step approach recently by Bianchini et al. using an indium(III) chloride catalyzed Povarov reaction. ${ }^{[62]}$ 


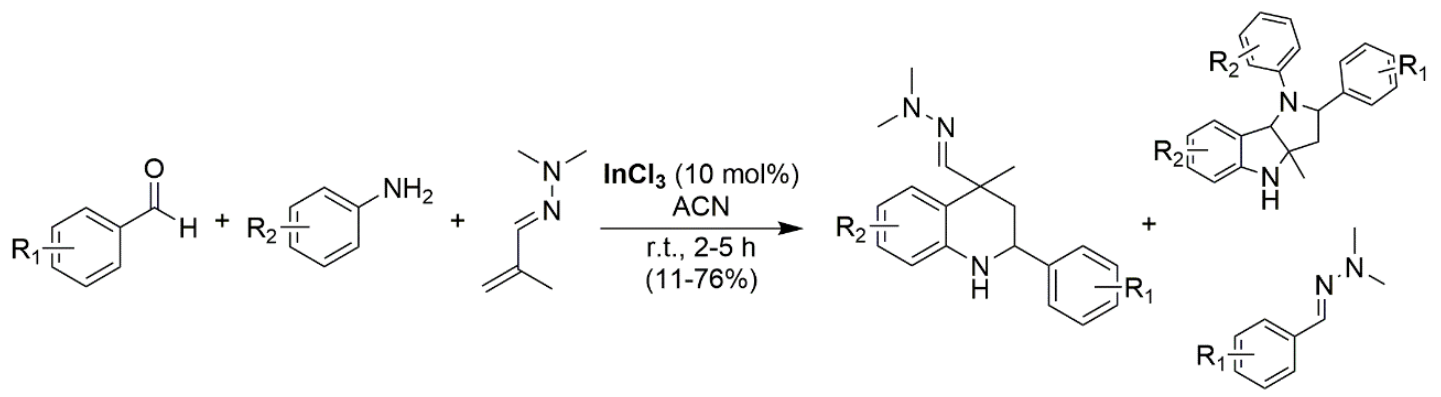

Scheme 23: $\operatorname{lnCl}_{3}$-catalyzed 1,2,3,4-tetrahydroquinoline derivatives.

Siddiqui et al. applied indium(III) bromide in a three-component reaction between $\mathrm{N}$-methylisatin, benzyl alkynes and phenacyl bromides (Scheme 24A). This reaction, which proceeds under mild conditions, can afford a considerable diversity of spirodihydrofuran-oxindole derivatives (12 examples) in good to excellent yields. ${ }^{[63]}$

The same catalyst was applied, at a higher loading, for the three-component reaction between alkynyl enones, secondary amines and aldehydes (Scheme 24B), leading to the formation of cyclopenta[c]furans (18 examples). In this work, other indium salts, namely indium(III) chloride and indium triflate were also evaluated, but they achieved lower yields using the same reaction conditions. This versatile approach occurs via indium catalyst activation of the enone moiety, which reacts with an in situ formed enamine (resulting from the reaction of the aldehyde and secondary amine), leading to a synthetic intermediate which undergoes two sequential cyclizations, affording the final products with high diastereoselectivity, with the yields being highly dependent on the substitution pattern of the starting materials. ${ }^{[64]}$

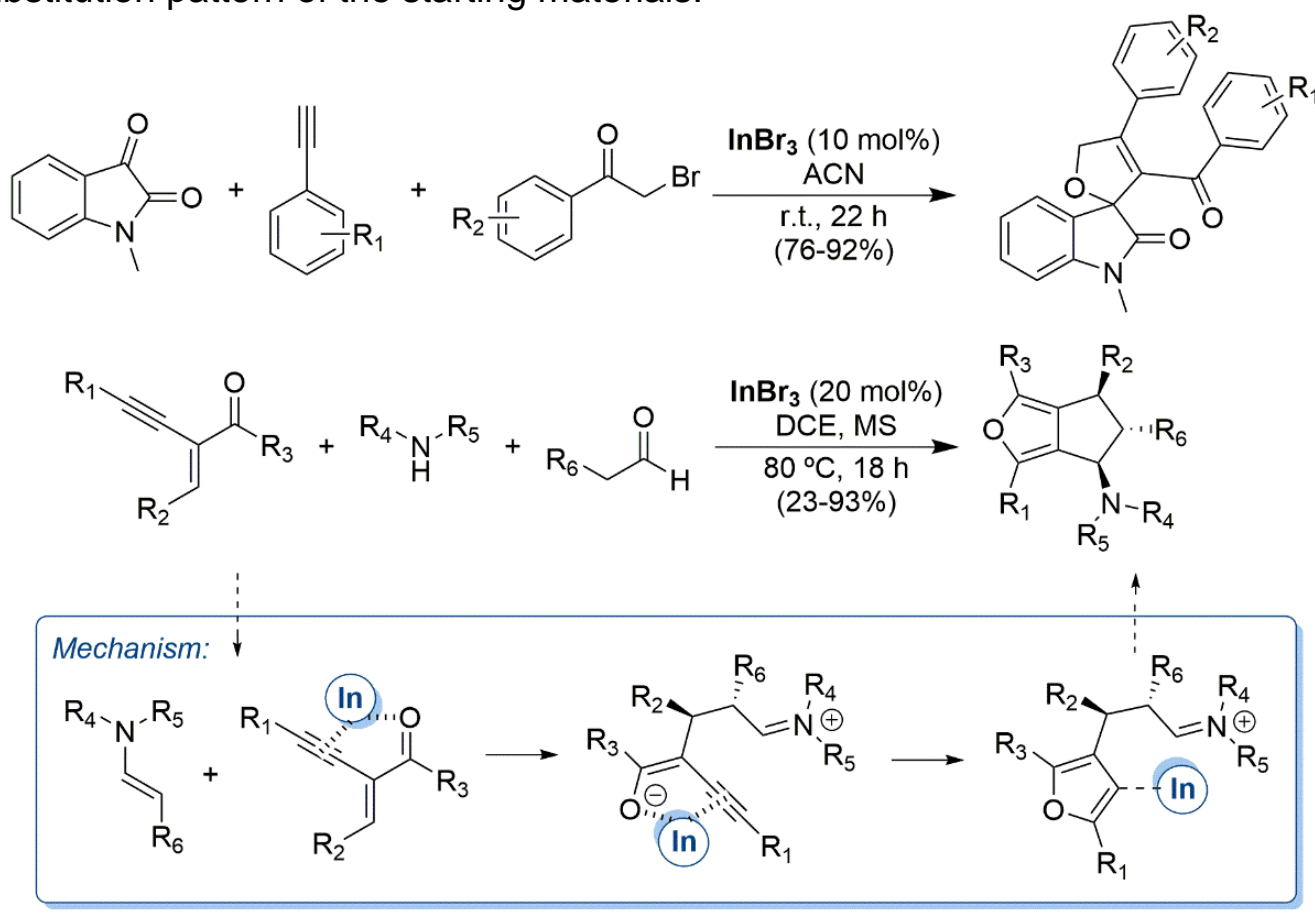

Scheme 24: $\operatorname{lnBr}_{3}$-catalyzed MCRs. 
Indium triflate was used for the synthesis of spiro-hexahydropyrimidines (16 examples) which occurred by way of a pseudo-six component reaction (Scheme 25A). Briefly, formaldehyde (three equivalents), cyclic ketones and anilines (two equivalents) reacted via imine formation (between formaldehyde and aniline), which is then attacked by an in situ generated enolate, affording a $\beta$-amino carbonyl synthetic intermediate. The reaction proceeds in the same manner, through the addition of a second imine unit, forming a propane-1,3-diamine intermediate, which through condensation with a third formaldehyde equivalent affords the final products in moderate to good yields, and with the possibility to recycle the catalyst. ${ }^{[65]}$

In another example, a pseudo-three component reaction, involving terminal phenyl alkynes (two equivalents) and methoxyphenols, catalyzed by indium triflate under microwave irradiation, afforded 15 products. Interestingly, the position of the methoxyl group in the phenol ring determines two different possible outcomes: when 4methoxyphenol is used $1 \mathrm{H}$-inden-4-ol derivatives (5 examples) are obtained (Scheme 25B) and when other methoxyphenols are used $4 \mathrm{H}$-chromene derivatives (10 examples) (Scheme 25C) are obtained. The reaction times are short irrespective of the methoxyphenol used. ${ }^{[66]}$

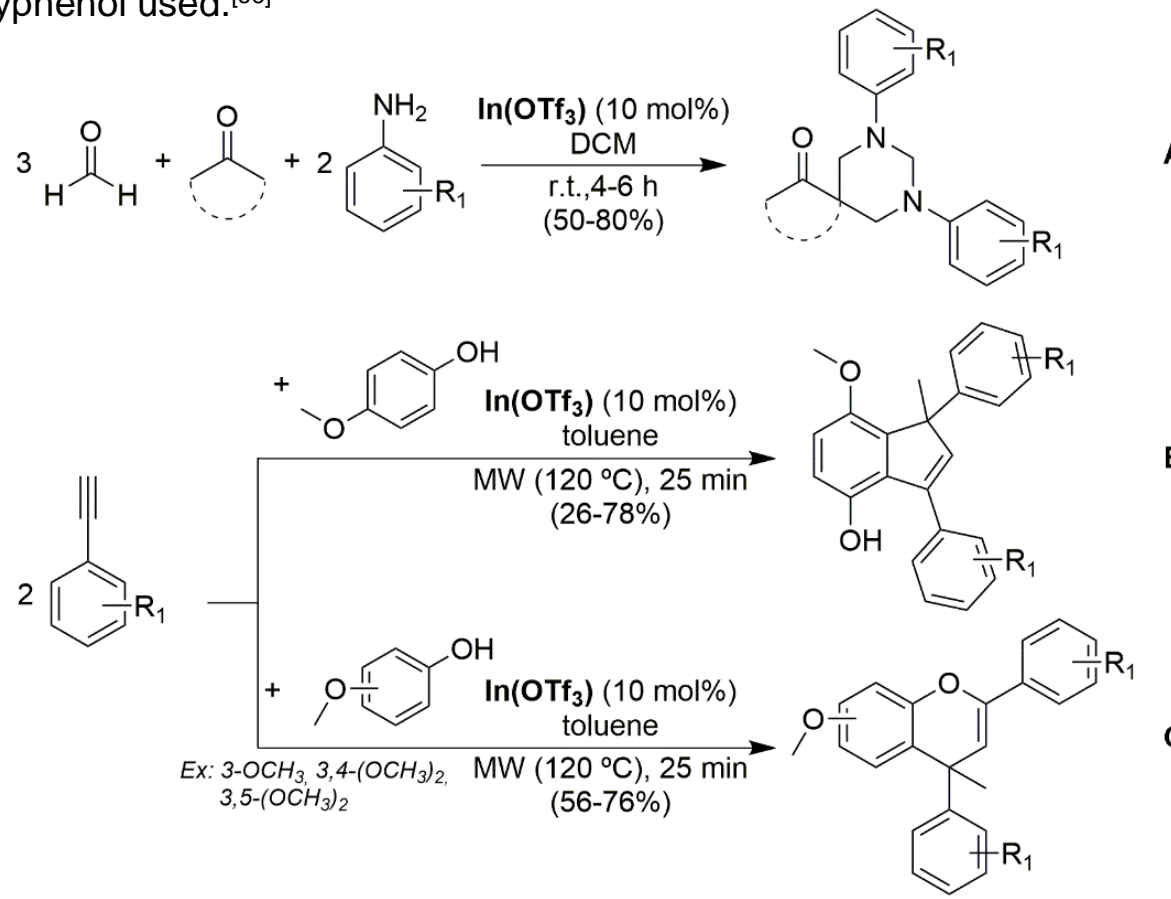

A)

B)

Scheme 25: $\ln \left(\mathrm{OTf}_{3}\right)$-catalyzed MCRs.

Indium powder can also be used as catalyst. Patel et al. described the application of this simple catalyst for the synthesis of piperazinyl-2-(benzo)thiophen/furan-2-ylacetonitriles (24 examples). This synthetic approach, which occurs via a Strecker reaction, not only provides these valuable scaffold in very good yields, but importantly it 
occurs under environmentally benign conditions, since the reaction occurs in water at room temperature (Scheme 26). ${ }^{[67]}$


$\mathrm{X}=\mathrm{O}, \mathrm{S}$

Scheme 26: Indium powder catalyzed MCR involving a key Strecker reaction.

\section{SUMMARY AND OUTLOOK}

Although not commonly described in the literature for its catalytic applications, indium is without a doubt an emerging valuable catalyst in the field of organic chemistry due to its Lewis acid properties. The combination of indium properties as a catalyst, displayed by simple, cheap and safe commercially available salts, indium powder to more complex and less explored realms, such as indium-based MOFs and NPs, and the versatility of multicomponent reactions, allows the effective synthesis of many organic compounds, such as Ugi and Passerini adducts, propargylamines and several relevant heterocycles, in one step, high yields and often short reaction times. These advantages are in line with several Green Chemistry Principles, showcasing that indium impact in synthetic methodologies goes far beyond principle number 9 - Catalysis - but has the potential to increase processes sustainability and show an improvement in virtually all Green Chemistry principles. We can also envision the application of indium, associated with chiral ligands, in asymmetric catalytic multicomponent reactions, an unexplored domain so far. In this work, we have revised a decade of research work in the field of indium-catalysis, and we anticipate that it will have an even bigger contribution in the years to come, in such fields as catalysis and synthetic organic chemistry.

\section{AKNOWLEDGEMENTS}

P. Brandão acknowledges FCT for the PhD grant PD/BD/128490/2017 - CATSUS FCT-PhD Program. Coimbra Chemistry Centre (CQC) supported by the Portuguese Agency for Scientific Research, "Fundação para a Ciência e a Tecnologia" (FCT) through project UIDB/00313/2020, co-funded by COMPETE2020-UE. This work was also financed by the FEDER Funds through the Operational Competitiveness Factors Program - COMPETE and by National Funds through FCT - Foundation for Science and Technology within the scope of the project UIDB/50006/2020. 
[1] a) F. Reich, T. Richter, J. Prakt. Chem. 1863, 90, 172-176; b) F. Reich, T. Richter, J. Prakt. Chem. 1864, 92, 480-485.

[2] S. Dagorne, R. Wehmschulte, ChemCatChem 2018, 10, 2509-2520.

[3] J. S. Yadav, A. Antony, J. George, B. V. Subba Reddy, Eur. J. Org. Chem. 2010, 2010, 591 605.

[4] J. P. Sestelo, L. A. Sarandeses, M. M. Martínez, L. Alonso-Marañón, Org. Biomol. Chem. 2018, 16, 5733-5747.

[5] a) J. S. Yadav, A. Antony, J. George, B. V. Subba Reddy, Curr. Org. Chem. 2010, 14, 414424; b) W. Zhan, Y. Guo, X. Gong, Y. Guo, Y. Wang, G. Lu, Chinese J. Catal. 2014, 35, 12381250; c) P. J. Tambade, Y. P. Patil, B. M. Bhanage, Curr. Org. Chem. 2009, 13, 1805-1819.

[6] C. G. Frost, J. P. Hartley, D. Griffin, Tetrahedron Lett. 2002, 43, 4789-4791.

[7] a) C. G. Frost, J. P. Hartley, Mini Rev. Org. Chem. 2004, 1, 1-7; b) Z.-L. Shen, S.-Y. Wang, Y.-K. Chok, Y.-H. Xu, T.-P. Loh, Chem. Rev. 2013, 113, 271-401; c) L. M. Aguirre-Diaz, D. Reinares-Fisac, M. Iglesias, E. Gutierrez-Puebla, F. Gandara, N. Snejko, M. A. Monge, Coord. Chem. Rev. 2017, 335, 1-27.

[8] a) S.-L. Chen, S.-J. Ji, T.-P. Loh, Tetrahedron Lett. 2003, 44, 2405-2408; b) T.-P. Loh, S.-L. Chen, Org. Lett. 2002, 4, 3647-3650; c) A. Dondoni, A. Massi, S. Sabbatini, Chemistry -A European Journal 2005, 11, 7110-7125.

[9] M. S. Singh, K. Raghuvanshi, Tetrahedron 2012, 68, 8683-8697.

[10] a) W. Zhang, W.-B. Yi, in Pot, Atom, and Step Economy (PASE) Synthesis, Springer International Publishing, Cham, 2019, pp. 27-40; b) J. E. Biggs-Houck, A. Younai, J. T. Shaw, Curr. Opin. Chem. Biol. 2010, 14, 371-382; c) C. S. Graebin, F. V. Ribeiro, K. R. Rogério, A. E. Kümmerle, Curr. Org. Synth. 2019, 16, 855-899; d) S. Zhi, X. Ma, W. Zhang, Org. Biomol. Chem. 2019, 17, 7632-7650.

[11] a) A. Dömling, Chem. Rev. 2006, 106, 17-89; b) T. Zarganes-Tzitzikas, A. L. Chandgude, A. Dömling, Chem. Rec. 2015, 15, 981-996; c) T. Zarganes-Tzitzikas, A. Dömling, Org. Chem. Front. 2014, 1, 834-837.

[12] a) Z.-Q. Liu, Curr. Org. Chem. 2014, 18, 719-739; bl. Ugi, R. Meyr, U. Fetzer, C. Steinbruckner, Angew. Chem. 1959, 71, 373-388.

[13] a) P. Brandão, A. J. Burke, Chim. Oggi - Chem. Today (Monographic special issue: Catalysis \& Biocatalysis) 2019, 37, 21-25; b) P. Brandão, A. J. Burke, Chim. Oggi - Chem. Today 2019, 37, 18-21.

[14] T. R. Ibarra-Rivera, M. A. Rentería-Gómez, E. Nieto-Sepúlveda, R. Gámez-Montaño, V. M. Rivas Galindo, E. Hernandez-Fernandez, Synth. Commun. 2016, 46, 509-515.

[15] L. A. Polindara-García, D. Montesinos-Miguel, A. Vazquez, Org. Biomol. Chem. 2015, 13, 9065-9071.

[16] G. Flores-Constante, A. C. Sánchez-Chávez, L. A. Polindara-García, Eur. J. Org. Chem. 2018, 2018, 4586-4591.

[17] L. A. Polindara-García, E. Juaristi, Eur. J. Org. Chem. 2016, 2016, 1095-1102.

[18] M. Passerini, L. Simone, Gazz. Chim. Ital. 1921, 51, 126-129.

[19] K. Lingaswamy, P. R. Krishna, Y. L. Prapurna, Synth. Commun. 2016, 46, 1275-1282.

[20] L. M. Aguirre-Diaz, M. Iglesias, N. Snejko, E. Gutierrez-Puebla, M. A. Monge, Chem. Eur. J. 2016, 22, 6654-6665.

[21] D. Reinares-Fisac, L. M. Aguirre-Diaz, M. Iglesias, E. Gutierrez-Puebla, F. Gandara, M. A. Monge, Dalton Trans. 2019, 48, 2988-2995.

[22] Y. M. Tian, L. M. Tian, X. He, C. J. Li, X. S. Jia, J. Li, Org. Lett. 2015, 17, 4874-4877.

[23] a) K. Groebke, J. Hunziker, W. Fraser, L. Peng, U. Diederichsen, K. Zimmermann, A. Holzner, C. Leumann, A. Eschenmoser, Helv. Chim. Acta 1998, 81, 375-474; b) C. Blackburn, B. Guan, P. Fleming, K. Shiosaki, S. Tsai, Tetrahedron Lett. 1998, 39, 36353638; c) H. Bienaymé, K. Bouzid, Angew. Chem. Int. Ed. 1998, 37, 2234-2237; d) A. Boltjes, A. Dömling, Eur. J. Org. Chem. 2019, 2019, 7007-7049. 
[24] N. Devi, D. Singh, Honey, S. Mor, S. Chaudhary, R. K. Rawal, V. Kumar, A. K. Chowdhury, V. Singh, RSC Adv. 2016, 6, 43881-43891.

[25] N. Devi, D. Singh, R. K. Sunkaria, C. C. Malakar, S. Mehra, R. K. Rawal, V. Singh, ChemistrySelect 2016, 1, 4696-4703.

[26] S. Swami, A. Agarwala, R. Shrivastava, Mol. Divers. 2017, 21, 81-88.

[27] a) V. A. Peshkov, O. P. Pereshivko, E. V. Van der Eycken, Chem. Soc. Rev. 2012, 41, 37903807; b) I. Jesin, G. C. Nandi, Eur. J. Org. Chem. 2019, 2019, 2704-2720.

[28] T. L. da Silva, R. S. Rambo, D. D. Rampon, C. S. Radatz, E. V. Benvenutti, D. Russowsky, P. H. Schneider, J. Mol. Catal. A Chem. 2015, 399, 71-78.

[29] B. V. S. Reddy, P. S. Reddy, Y. J. Reddy, J. S. Yadav, Tetrahedron Lett. 2011, 52, 57895793.

[30] M. M. Sarmah, D. Bhuyan, D. Prajapati, Synlett 2013, 24, 2245-2248.

[31] B. Das, P. Jangili, J. Kashanna, R. A. Kumar, Synthesis 2011, 3267-3270.

[32] X. L. Zhang, Q. P. Wu, Q. S. Zhang, J. Chem. Res. 2013, 697-700.

[33] Y. Gu, Green Chem. 2012, 14, 2091-2128.

[34] a) N. V. Lakshmi, S. E. Kiruthika, P. T. Perumal, Synlett 2011, 1389-1394; b) N. V. Lakshmi, S. E. Kiruthika, P. T. Perumal, Can. J. Chem. 2013, 91, 479-485.

[35] S. Samai, G. C. Nandi, M. S. Singh, Tetrahedron 2012, 68, 1247-1252.

[36] S. B. Dongare, H. V. Chavan, D. N. Surwase, P. S. Bhale, Y. B. Mule, B. P. Bandgar, J. Chin. Chem. Soc. 2016, 63, 323-330.

[37] D. N. Survase, H. V. Chavan, S. B. Dongare, S. D. Ganapure, V. B. Helavi, Iran. Chem. Commun. 2017, 5, 105-114.

[38] A. M. Jadhav, S. G. Balwe, J. S. Kim, K. T. Lim, Y. T. Jeong, Tetrahedron Lett. 2019, 60, 560-565.

[39] I. Hueso-Falcon, A. Amesty, P. Martin, M. Lopez-Rodriguez, L. Fernandez-Perez, A. Estevez-Braun, Tetrahedron 2014, 70, 8480-8487.

[40] A. Hantzsch, Ber. Deutsc. Chem. Ges. 1881, 14, 1637-1638.

[41] a) J.-P. Wan, Y. Liu, RSC Adv. 2012, 2, 9763-9777; b) H. G. O. Alvim, E. N. da Silva Júnior, B. A. D. Neto, RSC Adv. 2014, 4, 54282-54299; c) M. Leonardi, V. Estévez, M. Villacampa, J. C. Menéndez, Synthesis 2019, 51, 816-828.

[42] S. Maiti, V. Sridharan, J. C. Menendez, J. Comb. Chem. 2010, 12, 713-722.

[43] N. Mahajan, A. Sambyal, A. P. S. Pannu, T. K. Razdan, Tetrahedron Lett. 2011, 52, 12651268.

[44] A. A. Konczyk, J. Szawkalo, J. K. Maurin, Z. Czarnocki, Helv. Chim. Acta 2013, 96, 13481354.

[45] A. Cores, V. Estevez, M. Villacampa, J. C. Menendez, RSC Adv. 2016, 6, 39433-39443.

[46] L. M. Reddy, P. Chandrashekar, A. R. Reddy, C. K. Reddy, Russ. J. Gen. Chem. 2015, 85, 155-161.

[47] B. Das, D. B. Shinde, B. S. Kanth, G. Satyalakshmi, Synthesis 2010, 2823-2827.

[48] S. E. Tsai, W. P. Yen, Y. T. Li, Y. T. Hu, C. C. Tseng, F. F. Wong, Asian J. Org. Chem. 2017, 6, 1470-1475.

[49] I. R. Siddiqui, S. Shamim, D. Kumar, Shireen, M. A. Waseem, New. J. Chem. 2012, 36, 2209-2214.

[50] R. S. Thombal, Y. R. Lee, Org. Lett. 2018, 20, 4681-4685.

[51] V. D. Patil, J. S. Thakur, S. Mhatre, M. Gole, A. Jaiswal, Synth. React. Inorg. M. 2013, 43, 471-478.

[52] S. Santra, M. Rahman, A. Roy, A. Majee, A. Hajra, Catal. Commun. 2014, 49, 52-57.

[53] A. Sahu, S. Mishra, P. Sahu, A. Gajbhiye, R. K. Agrawal, Curr. Organocatalysis 2018, 5, 137-144.

[54] M. Dabiri, Z. N. Tisseh, A. Bazgir, Dyes Pigm. 2011, 89, 63-69.

[55] G. C. Nandi, S. Samai, M. S. Singh, Synlett 2010, 1133-1137. 
[56] L. Zhang, X.-M. Peng, G. L. V. Damu, R.-X. Geng, C.-H. Zhou, Med. Res. Rev. 2014, 34, 340437.

[57] K. C. Majumdar, D. Ghosh, S. Ponra, Synthesis 2013, 45, 2983-2988.

[58] H. H. Nguyen, T. A. Palazzo, M. J. Kurth, Org. Lett. 2013, 15, 4492-4495.

[59] I. R. Siddiqui, S. Shamim, A. Singh, V. Srivastava, S. Yadav, Arkivoc 2010, 232-241.

[60] D. Facoetti, G. Abbiati, M. Dell'Acqua, E. Rossi, Tetrahedron 2011, 67, 6833-6837.

[61] V. Sridharan, P. Ribelles, V. Estevez, M. Villacampa, M. T. Ramos, P. T. Perumal, J. C. Menendez, Chem. Eur. J. 2012, 18, 5056-5063.

[62] G. Bianchini, P. Ribelles, D. Becerra, M. T. Ramos, J. C. Menéndez, Org. Chem. Front. 2016, 3, 412-422.

[63] I. R. Siddiqui, Rahila, S. Shamim, P. Rai, Shireen, M. A. Waseem, A. A. H. Abumhdi, Tetrahedron Lett. 2013, 54, 6991-6994.

[64] S. R. Pathipati, A. van der Werf, L. Eriksson, N. Selander, Angew. Chem. Int. Ed. 2016, 55, $11863-11866$.

[65] A. Dandia, A. K. Jain, S. Sharma, Tetrahedron Lett. 2012, 53, 5270-5274.

[66] V. K. Rao, P. Kaswan, K. Parang, A. Kumar, Org. Biomol. Chem. 2015, 13, 11072-11077.

[67] R. V. Patel, J. K. Patel, S. H. Nile, S. W. Park, Lett. Drug Des. Discov. 2013, 10, 462-470. 


\section{Table of Contents}

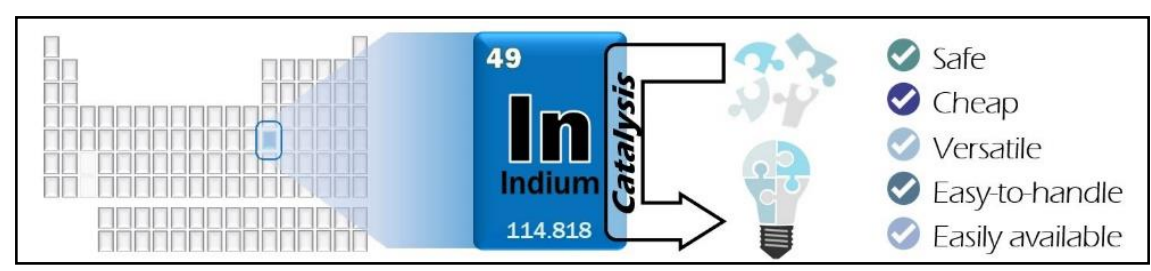

Indium catalysis applied to Multicomponent Reactions is a thriving field in organic synthesis. In this work, we revisited the main achievements in indium-catalyzed multicomponent reactions, showcasing the versatility of the different indium-based catalysts, from simple indium powder, to inexpensive and easily available indium salts, to more complex heterogeneous catalytic systems, such as indium-based metal-organic frameworks and nanoparticles.

Keywords: Indium Catalysis; Multicomponent reactions 